\title{
SOCIO-DEMOGRAPHIC FACTORS ASSOCIATED WITH SELF-PROTECTING BEHAVIOR DURING THE COVID-19 PANDEMIC
}

\author{
Nicholas W. Papageorge \\ Matthew V. Zahn \\ Michèle Belot \\ Eline van den Broek-Altenburg \\ Syngjoo Choi \\ Julian C. Jamison \\ Egon Tripodi \\ Working Paper 27378 \\ http://www.nber.org/papers/w27378
NATIONAL BUREAU OF ECONOMIC RESEARCH
1050 Massachusetts Avenue
Cambridge, MA 02138
June 2020

We are grateful for helpful comments from Stefanie DeLuca, Barton Hamilton and Emma Kalish. Regarding author ordering, Papageorge and Zahn led this particular effort and are thus listed first. The remaining authors contributed equally and are listed in alphabetical order The views expressed herein are those of the authors and do not necessarily reflect the views of the National Bureau of Economic Research.

NBER working papers are circulated for discussion and comment purposes. They have not been peer-reviewed or been subject to the review by the NBER Board of Directors that accompanies official NBER publications.

(C) 2020 by Nicholas W. Papageorge, Matthew V. Zahn, Michèle Belot, Eline van den BroekAltenburg, Syngjoo Choi, Julian C. Jamison, and Egon Tripodi. All rights reserved. Short sections of text, not to exceed two paragraphs, may be quoted without explicit permission provided that full credit, including $\odot$ notice, is given to the source. 
Socio-Demographic Factors Associated with Self-Protecting Behavior during the Covid-19

Pandemic

Nicholas W. Papageorge, Matthew V. Zahn, Michèle Belot, Eline van den Broek-Altenburg, Syngjoo Choi, Julian C. Jamison, and Egon Tripodi

NBER Working Paper No. 27378

June 2020

JEL No. I1

\section{ABSTRACT}

Disease spread is in part a function of individual behavior. We examine the factors predicting individual behavior during the Covid-19 pandemic in the United States using novel data collected by Belot et al. (2020). Among other factors, we show that people with lower income, less flexible work arrangements (e.g., an inability to tele-work) and lack of outside space at home are less likely to engage in behaviors, such as social distancing, that limit the spread of disease. We also find evidence that region, gender and beliefs predict behavior. Broadly, our findings align with typical relationships between health and socio-economic status. Moreover, they suggest that the burden of measures designed to stem the pandemic are unevenly distributed across sociodemographic groups in ways that affect behavior and thus potentially the spread of illness. Policies that assume otherwise are unlikely to be effective or sustainable.

Nicholas W. Papageorge

Department of Economics

Johns Hopkins University 3400

N. Charles Street Baltimore,

MD 21218

and IZA

and also NBER

papageorge@jhu.edu

Matthew V. Zahn

Johns Hopkins University

Economics Department

Wyman Park Building

3400 N. Charles St Baltimore,

MD 21218

matthew.zahn@jhu.edu

Michèle Belot

European University Institute

and IZA

michele.belot@eui.eu

Eline van den Broek-Altenburg

The University of Vermont

Larner College of Medicine 89

Beaumont Avenue Burlington,

VT 05405

eline.altenburg@med.uvm.edu
Syngjoo Choi

Department of Economics

Seoul National University

1 Gwanak-ro Gwanak-gu

Seoul, Republic of Korea

syngjooc@snu.ac.kr

Julian C. Jamison

Department of Economics

University of Exeter Business School

Exeter EX4 4PU

United Kingdom

j.jamison@exeter.ac.uk

Egon Tripodi

European University Institute

egon.tripodi@eui.eu 


\section{Introduction}

The spread of illness is not solely a biological phenomenon. It is also a social one, driven in part by human behavior. In the presence of strong externalities, a concern is that individual behavior may not align with socially optimal outcomes (Posner and Philipson (1993)). This is especially salient in contexts where the costs of protective behaviors, i.e., behaviors that limit the spread of illness, are unevenly distributed across socio-demographic groups (Pampel, Krueger, and Denney (2010)). For instance, in the Covid-19 pandemic, individuals who face a relatively low risk of serious illness, but who are economically vulnerable (e.g., lacking comfortable housing, the ability to work from home, and so on) may not follow recommendations or directives to engage in protective behaviors, such as wearing a mask or social-distancing. This potentially puts high-risk groups in danger of infection and prolongs the pandemic.

The socially optimal amount of protective behaviors - the levels that balance public health concerns with individual burdens and aggregate economic costs - are not yet fully understood, and are unlikely to be for some time due to uncertainty about the virus and about which behaviors most effectively prevent its spread (Manski (1999)). Compounding this uncertainty, we do not yet understand the full extent of the economic and social costs of the pandemic itself and measures taken to avoid it, ranging from job losses, shuttered businesses, gaps in schooling, violence, and addiction, among others (Fairlie, Couch, and Xu (2020), Alon et al. (2020), Mongey, Pilossoph, and Weinberg (2020), Coibion, Gorodnichenko, and Weber (2020), Viner et al. (2020)). Never-the-less, understanding what factors affect individuals' incentives to engage in protective behaviors will be of critical importance as we develop effective and humane policy, evaluate the current epidemic, make plans to emerge from it, and begin to prepare for future pandemics.

This paper examines factors predicting individual self-protecting behaviors during the Covid-19 pandemic. The factors we study include income, socio-demographic variables, 
pre-pandemic health characteristics, job and income losses, work arrangements (e.g., the ability to tele-work) and housing, along with beliefs and perceptions about the pandemic (e.g., whether individuals perceive social-distancing to be an effective measure and the consequences of infection). We study how these factors relate to several behavior changes, including social-distancing, mask-wearing and hand-washing. We focus on individuals living in the United States using unique survey data collected during the last week of April 2020 and detailed in Belot et al. (2020). The data set follows roughly 6,000 individuals in 6 different countries and includes about 1,000 individuals from four different states in the US: California, Florida, New York, and Texas.

We begin by documenting a striking and robust pattern apparent in the data: higher income is associated with higher levels of self-protective behaviors. Figure 1 illustrates this relationship. The figure considers three measures: (i) whether the respondent changed any behavior at all in response to the pandemic; (ii) whether the respondent increased socialdistancing, which includes avoiding public spaces, running fewer errands, and visiting friends and family less often; and (iii) whether the respondent increased hand-washing or maskwearing. The data have information on a host of additional behaviors (and similar income gradients emerge when we examine them). We choose to focus on these three measures because they illustrate the wide range of possible self-protective behaviors: the first is very broad, including any change in behavior at all; the second is a relatively high-cost activity; and the third is a relatively low-cost activity. Using these measures, we show that on average individuals in the fifth income quintile (quintile mean $\$ 233,895$ ) are between 13 and 19 percentage points (16-54\%) more likely to engage in protective behaviors compared to individuals in the first income quintile (quintile mean $\$ 13,775){ }^{1}$

Our main analysis explores the relationships between income, the pandemic, and selfprotective behaviors in two ways. First, we show how income relates to initial consequences

\footnotetext{
${ }^{1}$ Quintile means come from the Tax Policy Center, administered by the Urban Institute and Brookings Institution.
} 
of the pandemic along with other factors that could affect social-distancing and other selfprotective behaviors. We show that lower-income respondents are more likely to lose their job or some portion of their income due to the pandemic (or to expect to soon). They are also less likely to be able to work from home or have access to open space where they reside.

Next, we examine which socio-demographic characteristics predict self-protecting behaviors. In particular, we estimate a series of linear probability models in which a selfprotecting behavior is the outcome and the predictor variables include income along with different sets of additional variables, culminating in a final specification including income along with all variables. Several patterns emerge. Work arrangements and housing characteristics, particularly transitioning to tele-working and access to outside space at home, are associated with adopting more self-protecting behaviors. We also find that income losses due to the pandemic are associated with increases in the behaviors that we examine. Surprisingly, we find no meaningful patterns between pre-existing health conditions and increases in self-protective actions. We also show that males and respondents from Florida and Texas are less likely to engage in self protective behaviors compared to females and respondents from California and New York, respectively. Moreover, beliefs about the effectiveness of social distancing along with perceived benefits (e.g., more time spent with family) correlate with increases in self-protective behaviors. Finally, we demonstrate that the income gradient is only partially explained by the inclusion of these variables. The size of the income coefficient estimates are fairly stable across specifications where different sets of controls included.

Broadly, our findings are consistent with two key ideas. One, the initial economic consequences of the pandemic are particularly harmful to low-income individuals. Two, behaviors to stem the pandemic could place relatively large burdens on individuals with lower incomes. For example, higher-income individuals are more likely to report being able to work from home and more likely to have transitioned to tele-working instead of losing their job. As a result, self-protective behaviors, such social-distancing, are more practical, comfortable, and feasible for people with more income, which is evident in Figure 1. 
This paper relates to a number of ongoing research efforts that are providing new information on the current pandemic and people's responses to it on a near-daily basis. ${ }^{2}$ To the degree our questions and findings overlap, we provide crucial replication in an era of rapid-response, hastily-completed research. When questions or focus differs, we provide new information that other efforts do not. Finally, if we provide contradictory answers to similar questions, this is also important since it highlights where further research is needed. Existing research ranges from other commissioned surveys to formal economic models. For example, Adams-Prassl et al. (2020a) conducted a nationally representative survey of the UK, US, and German population on the labor market impacts of Covid-19. Adams-Prassl et al. (2020b) examines the impacts of Covid-19 lockdowns on mental health. Other studies have focused on the impacts of the Covid-19 pandemic on personal economic outcomes. Borjas (2020) examines how demographic factors influence testing and infections in the New York City area. Another example is Mongey, Pilossoph, and Weinberg (2020). The authors analyze which workers and jobs are most affected by social distancing measures. Closely related to this paper, Wozniak (2020) uses a unique U.S. data set, also publicly available, to show declines in well-being due to the pandemic and patterns between disease exposure and the decision to work or take protective measures. She finds people with Covid-19 exposure continue to work at similar rates as the non-exposed, and people with elevated risk for contracting the disease do not reduce work hours or take protective measures. We place greater attention on the associations between an individual's protective behaviors and their characteristics and beliefs, while she focuses more on protective behaviors through the lens of risks factors (i.e., an individual's susceptibility and potential spreading) and protective behaviors.

More broadly, this paper relates to a vast literature studying how socio-demographic characteristics associate with health and health behaviors. While our contribution reports evidence in a very specific context, the Covid-19 pandemic, it is noteworthy that many of the

\footnotetext{
${ }^{2}$ Because new research continues to emerge, we will augment our list of citations in later drafts of this paper.
} 
same relationships found in many other health contexts are evident here. ${ }^{3}$ In other words, well-documented socio-demographic differences in health behaviors - and resulting health disparities - extend to the current pandemic (Yancy (2020)). Understanding this could help to inform optimal policy during a pandemic. Moreover, what we learn about behavior during a pandemic, a period when stakes are high and shifts in behavior are swift and large, can help us to understand health behavior differences more generally. As a concrete example, if we learn that certain types of work arrangements prevent social-distancing, such arrangements may prevent a host of other healthy behaviors that are unrelated to the pandemic. In this way, the current pandemic can provide useful directions for future research on health behaviors and health disparities.

Finally, this paper relates to a literature examining the tension between individual behavior and public health in the presence of externalities. A key historical analogy is the HIV epidemic. ${ }^{4}$ In that context, reduction of risky sex behavior not only protected individuals, but also slowed the spread of the virus, which is socially beneficial. The social benefit means there is a positive externality and thus potentially a sub-optimally low level of safer sex. In the current context, the tension between private behavior and public health is exacerbated by the fact that many people asked to incur the most brutal economic and social costs of protective behaviors face relatively low personal risk of serious health problems. This opens up a host of broad and general ethical questions about who should bear the greatest costs to protect public health. It also casts doubt on the sustainability of policies that presume full compliance. ${ }^{5}$

The remainder of this paper proceeds as follows. First, we discuss our data source and

\footnotetext{
${ }^{3}$ Cutler, Lleras-Muney, and Vogl (2011) provide an excellent summary and overview of the socioeconomic status-health gradient literature.

${ }^{4}$ Papageorge (2016) and Chan, Hamilton, and Papageorge (2016) are two studies which examine the history of the HIV epidemic to make broader points about health. More generally, Cawley and Ruhm (2011) provide a summary of the literature that examines cases where individuals make a trade off between controllable behaviors and health outcomes.

${ }^{5}$ Many of these ideas were explored in a recent blog post by DeLuca, Papageorge, and Kalish (2020). The current study builds on this piece, in part by using data to test hypotheses it put forth.
} 
its preliminary analysis, highlighting patterns in the data. From there, we then discuss the results from our main analysis, which quantify the associations between individual characteristics and behavior changes. The final section concludes and describes further work in this area.

\section{$2 \quad$ Data and Summary Statistics}

We rely on recently-collected survey data from six different countries. In their accompanying paper (Belot et al. (2020)), the authors describe their sampling procedure and key features of the data. The United States sample, which is the focus of this paper, contains information on approximately one thousand individuals, roughly 250 from each of the following from four states: California, Florida, New York, and Texas. The survey was constructed to be nationally representative along gender, age, household income, and race. While the survey is representative along these characteristics, however, it is not a random sample of people in the US, which means estimates must be interpreted with care. For example, it would be inappropriate at this stage to interpret links between economic factors and behavior as causal.

Table 1 summarizes the socio-demographic characteristics and outcomes we study from the survey sample. $15 \%$ of respondents are non-white, $44 \%$ are male and about $39 \%$ are 56 years or older. $45 \%$ of respondents report at least one pre-existing health condition. Approximately $70 \%$ of respondents reported being employed. Among those that reported working, nearly 54\% work full time, $14 \%$ work part time and $82 \%$ are able to work from home at the time of the survey when the pandemic was well underway. Also among these respondents, $34 \%$ report shifting to tele-work, $38 \%$ are no longer working, and $20 \%$ reported no change in their employment situation. On average, respondents lost $\$ 770$ in household income due to the pandemic. ${ }^{6}$

\footnotetext{
${ }^{6}$ Some respondents reported very large income losses. Given the difficultly in determining whether these
} 
The survey contains two variables about labor status. The first asks about the current work arrangement and the second asks about changes due to the pandemic. Using these two variables, we construct a single measure that captures possible ways that the pandemic has affected individuals with different work arrangements. There are five possibilities: (i) "Never Worked" refers to individuals who were not working prior to or during the pandemic (e.g., retirees); (ii) "Stopped Working" refers to people who were working (full-time, part-time or self-employed) and stopped working due to the pandemic; (iii) "Began Tele-Working" refers to people who were employed prior to the pandemic and are still employed, but transitioned to working from home due to the pandemic; (iv) "Still Working" describes individuals who were working prior to the pandemic and whose work status has not changed; and (v) "Other" includes people who report working prior to the pandemic and also report "other" when asked how their work status has changed. We should note that roughly 17 individuals do not fit into any of the categories above due to contradictory answers. As an example, some respondents report not working before the pandemic and also transitioning to tele-working, which is difficult to categorize. ${ }^{7}$

Figure 2 summarizes this work status variable by age group and income quintile. As expected, we find that younger respondents tend to be more likely to begin tele-working whereas older workers are more likely to not be working before or during the pandemic. We also see that higher income people are more likely to transition to tele-working, while lower income people are more likely to either not be working before the pandemic or to have stopped working due to the pandemic. The share of respondents that were still working without any change was relatively stable across income quintiles. A deeper look into the survey finds an intuitive pattern. Those that were in lower income quintiles and reported still working belong to professions such as cashiers, packers and packagers, among others.

are actual losses or survey errors, we use a dummy variable to flag these values. There are 173 of these observations. Our results are robust to the inclusion of these observations. The only difference is the magnitude on the lost income coefficient. The number in the table reflects the average of the remaining values.

${ }^{7}$ If we include these observations in the "Other" category, our results remain unchanged. 
Those in higher quintiles that reported still working included lawyers, computer programmers and managers. These professions differ substantially in what they pay, but include people who have been deemed "essential workers." This explains the lack of an income gradient for this particular category.

The survey also includes information on beliefs and perceptions. Approximately $73 \%$ believe that social-distancing is either very effective or extremely effective, versus $24 \%$ who believe it is slightly or moderately effective. Only $3 \%$ of the sample believed social distancing was not effective at all. Almost 39\% of respondents believed it to be extremely effective. On average, respondents believe that $24 \%$ of the people in their locality are infected. This high number is driven by a mass of respondents reporting implausibly high numbers (including some saying over 90\%), which will be discussed below. ${ }^{8}$ Finally, about $84 \%$ perceive some benefits from the pandemic (e.g., getting to spend more time with family or reductions in pollution). As we show below, these perceptions predict behavior.

The survey measures behavior change in two ways. First, respondents are asked directly if they engaged in any self-protective behavior in response to the pandemic. About $88 \%$ report having done so. Second, the survey asks respondents to report how frequently they engaged in 15 different activities before the pandemic, at the start of the pandemic, and a few weeks after the pandemic began. These behaviors ranged from hand washing and eating healthy to visiting large open or closed spaces and visiting friends and family. Given this data structure, we observe how the respondents changed their behavior over time. For each behavior, respondents could answer (1) never, (2) rarely, (3) sometimes, (4) very often, or (5) always. Figure A.1 in the Appendix summarizes the average frequency with which respondents engaged in some of these behaviors at each time period. Consistent with Figure 3 , we see an increase in the average frequency of self protective behaviors from before the pandemic to weeks after the pandemic started. To get a sense of behavior change, we

\footnotetext{
${ }^{8}$ In some specifications, we experiment with dropping some extreme values under the assumption that they reflect respondent confusion. However, doing so does not alter our results.
} 
construct a count variable for each individual for the number of changes towards (or away from) self-protection from before the pandemic to a few weeks after it had begun, when the data were collected. Figure 3 plots the distribution of the resulting variable. The changes are normalized such that self-protecting changes are positive, while reducing such behaviors is recorded as negative. ${ }^{9}$ The median number of changes towards self-protection is 9 . We highlight two main takeaways from Figure 3. First, very few people exhibit a net decline in self-protective behaviors. Second, most people either do not change their behavior much at all (note the spike in the distribution at zero) or make a fairly large number of changes. Figure 4 presents a smoothed version of Figure 3 for the lowest and highest income quintiles. We find that a greater mass of low income people are not increasing their self protective behaviors. We see the opposite pattern for high income people, with a greater share of high income people increasing their self protective behaviors.

In our subsequent analysis, we focus on three measures of behavior change. The first is from the aforementioned question asking respondents directly if they changed their behavior in response to the epidemic. The second is a composite behavior variable for social distancing. We focus on: visiting large open spaces, visiting large closed spaces, attending large social gatherings, and visiting with friends or family. As we are mainly interested in how behaviors change, we look at how this social distancing composite changes over time. ${ }^{10}$ An increase in social distancing is defined as an above-median increase in the number of self-protecting improvements for the four behaviors of interest. The third measure focuses on changes in hand-washing and in wearing a mask.

In these analyses, we make four types of drops from the full US survey sample for our

\footnotetext{
${ }^{9}$ To fix ideas, suppose an individual answered 3 (sometimes) for hand washing and 3 (sometimes) for taking public transport before the pandemic and 5 and 4, respectively, during the pandemic. The increase in hand washing accounts for 2 increases in self protective behaviors and the increase in taking public transportation is recorded as a 1 increment decrease in self protective behaviors. Taken together this results in a net effect of $2-1=1$.

${ }^{10}$ Note that we drop respondents that were never engaging in these activities (i.e., were always social distancing) prior to the pandemic since they would have no way of increasing their social distancing measures in response to the pandemic. This means we lose 40-73 individuals, depending on the specification.
} 
analysis. First, we drop respondents who did not report an income quintile or gender (15 observations). Second, as discussed previously, our composite behavior dependent variables examine increases in behaviors. We drop respondents that were already engaging in these behaviors and had no ability to increase further (40 observations for social distancing and 73 for hand washing-mask wearing). The third set of drops are the outliers in local infection rate beliefs (36 observations). Finally, we drop about 17 respondents that did not map into our composite work status variable. For each dependent variable, we hold the analysis sample constant across specifications to facilitate comparisons. Thus for each outcome, we take the maximum number of observations that remain after these sets of drops.

\section{Results}

\subsection{Connecting Socio-demographic Characteristics to Income}

Table 2 summarizes the difference in means of several characteristics broken by income groups. Here, we have defined high income as the top three quintiles and low income as the bottom two quintiles. We find significant differences for most of these characteristics between high income and low income respondents. For example, non-white respondents were more likely to be low income than white respondents. We find no significant income differences for pre-existing health conditions, exposure to a person 56 years or older, and beliefs in the effectiveness of social distancing.

Figure 5 explores expected losses to labor and household income by labor status and income quintile. Expected losses to labor income are a much larger share of income for low income respondents. For example, people in the first income quintile reported expected labor income losses of over $10 \%$ while respondents in the fifth income quintile expected losses of no more than 5\%. We observe a similar pattern when looking at expected household income losses. First quintile expected losses range from nearly $20 \%$ to about $25 \%$ while fifth 
quintile losses range from $10 \%$ to just under 15\%. Figure 6 assesses losses that have already occurred. We observe a similar relationship between income quintile and the magnitude of income losses. The second panel examines job losses due to the pandemic. We see that the lowest-income respondents had the lowest amount of job security and the highest probability of temporary unemployment. An interesting pattern is that higher income individuals were the most likely to permanently lose their jobs, despite also having the highest level of job security across all income quintiles. This may reflect selection: higher-income jobs are more secure in general so a job loss reflects a large and permanent shift, e.g., a bankruptcy.

Next, we consider work arrangements by income. Figure 7 consists of three panels, which plot labor status (full time, part time, self employed or not working), whether respondents have experienced a change in work status and how well they can work from home, respectively. According to the figure, full time employment, the ability to work from home and a change in work status to tele-working all rise with income. Lower-income people are more likely to report either that they stopped working or that they experienced no change in work status (which includes not having switched to tele-working). For example, nearly $75 \%$ of respondents in the fifth income quintile are working full-time. About the same percentage of respondents in the first quintile are not working. More than $50 \%$ of respondents in the fifth income quintile reported transitioning to tele-work post-pandemic, whereas only $10 \%$ of those in the first quintile did so. This pattern appears consistent with the fact that nearly $40 \%$ of low income respondents report being unable to work from home. ${ }^{11}$

The other broad categories of socio-demographic characteristics that are potentially associated with income and behavior changes are pre-existing health conditions, household features, and beliefs related to the pandemic. From Table 1 we know that $43 \%$ of survey respondents reported having a pre-existing health condition such as diabetes, high blood pressure, heart disease, or asthma. Given strong income-health gradients found in other

\footnotetext{
${ }^{11}$ We also ran a multinomial logit model where the outcome variable is our work status variable in order to study which factors predict which types of work changes and find that these patterns hold. These results are available upon request.
} 
literature, this pattern is surprising and may reflect that the sample is not representative of the US in terms of the relationship between income and health. In contrast, housing is strongly related to income. Higher-income respondents are far more likely to live in homes (versus apartments) and to have access to open air where they reside compared to lowerincome respondents. As we noted earlier, we do not observe a pattern between income and beliefs in the effectiveness of social distancing. ${ }^{12}$ Across all income quintiles, $70 \%-78 \%$ of respondents believe social distancing is either very effective or extremely effective. ${ }^{13}$

The survey data also contain respondents' beliefs about various rates related to the disease such as infection rates, likelihood of contracting the disease, and so on. However, it is difficult to interpret responses. For example, consider beliefs about the local infection rate. The distribution of these beliefs is presented in Figure A.2. We can see that many respondents report implausibly small and large numbers. This could reflect several factors, including misinformation about the spread of illness, difficulties with probabilistic thinking, which is well-documented in the literature (see e.g., Barth, Papageorge, and Thom (2020), Lillard and Willis (2001), Delavande, Perry, and Willis (2006), etc.), fatalistic beliefs (e.g., Akesson et al. (2020)), optimism about herd immunity, etc. ${ }^{14}$ In any case, these interpretational difficulties will limit conclusions we can draw using some of the beliefs variables.

\subsection{Factors Associated with Behavior Change}

Our analysis until now shows that several factors are related to income. These factors could potentially help to explain differences across income groups in self-protective behaviors depicted in Figure 1. In this section, we explore which socio-demographic characteristics are associated with behavior changes.

\footnotetext{
${ }^{12}$ We measure a respondent's belief in social distancing as the average of their beliefs about the effectiveness of shutting down non-essential businesses, limiting mobility outside the home, and forbidding mass gatherings.

${ }^{13}$ These patterns are explored further in Tables A.1, A.2, A.3, and A.4.

${ }^{14}$ Indeed, we must leave open the possibility that, due to our lack of knowledge about the illness, implausibly-high answers are correct.
} 
To begin, Table 3 summarizes the difference in means across different characteristics for those who increased social distancing behavior according to our metric. We find significant differences between males and females and between those who believe in the effectiveness of social distancing. These findings suggest that women are more likely than men to increase social distancing as are those who believe strongly in the effectiveness of social distancing. There are significant differences between those who have not stopped working and those that are still working. We do not find any other significant differences across individual characteristics.

For our main analysis, we examine three outcomes: any behavior change, social distancing, and mask-wearing or hand-washing. For each outcome, we estimate linear probability models as a function of income and different sets of explanatory variables. Our main findings are summarized in Table 4. In general, we find that income, work arrangements such as tele-working, lost income, and beliefs about the effectiveness of social distancing are significantly associated with the self-protective measures we examine. Detailed results are presented in Tables A.5, A.6, and A.7 in the Appendix. In each table, all columns include income quintiles as explanatory variables. Column (1) includes only income, Column(2) adds in socio-demographic characteristics, Column (3) adds pre-existing health conditions, Column (4) brings in housing characteristics, Column (5) work arrangements and economic loss characteristics, Column (6) adds in beliefs about social distancing and local infection rates and perceived benefits from the pandemic. Finally, in Column (7) we include all of these sets of controls in a single specification. We will discuss each of these columns in the following subsections. ${ }^{15}$

\footnotetext{
${ }^{15}$ We examined other characteristic associations beyond what is presented in the paper. These results are available upon request.
} 


\subsubsection{Income}

Across all three of our dependent variables we find strong, statistically significant associations with income. Higher income individuals are more likely to engage in the behavior we examine. To fix ideas, relative to the first income quintile, a member of the fifth income quintile is 10\%-15\% more likely to change their behaviors, $14 \%-28 \%$ more likely to increase social distancing behaviors, and 18\%-28\% more likely to increase hand washing or mask wearing. We find that these income effects are fairly robust to the inclusion of controls. From the baseline to the case where we include all of our controls, the size of the coefficient estimates remain fairly stable as we add additional variables, which means that these other factors do not fully explain the income gradient.

\subsubsection{Gender, Age, Race and Location}

The next set of controls we include are gender, age, race and state. We do not find many significant associations between these factors and the change behaviors outcome. In the baseline case we see negative associations between males, people 56 years or older, and some regional effects. However, most of these relationships disappear when other variables are added to the analysis. We find more robust significance for the increased social distancing behavior. We find strong negative associations between males, and respondents from Florida and Texas, which maintain significance once other controls are added. To fix ideas, we find that males are $15 \%$ less likely than females to increase social distancing. Similarly, we find that relative to respondents from California, people in Texas and Florida tended to be $16 \%$ and $12 \%$ less likely to increase social distancing, respectively. Finally, we find positive significant associations between race and people 56 years or older for the hand washingmask wearing outcome. Specifically, we find that Black respondents are $13 \%$ more likely than white respondents to increase hand washing or mask wearing. ${ }^{16}$ We find a similarly

\footnotetext{
${ }^{16} \mathrm{~A}$ data set that over-samples non-white individuals would potentially reveal other differences by race or ethnicity in the likelihood of engaging in self-protective behaviors.
} 
sized relationship for those 56 years or older. It is interesting that we pick up these effects for increased hand washing or mask wearing. This may be reflect the fact that of the three activities we examine, this one is a relatively low-cost way to self protect for people who face risks, but are unable to engage in higher-cost, less practical activities, such as socialdistancing.

\subsubsection{Health}

We also examine various pre-existing health conditions, including diabetes, high blood pressure, heart disease, asthma, allergies, and other conditions. Overall, and surprisingly, these variables are not strongly correlated to behavior change. ${ }^{17}$ Yet, it is surprising that health conditions more strongly associated with serious illness (e.g., diabetes, asthma, or high blood pressure) are not associated with behavior change. An exception is that we find a robust significant association between allergies and increases in hand-washing and mask-wearing. A number of factors could explain this, including the possibility that people with allergies could feel they are becoming ill even if they are not and thus be more willing to take precautions.

\subsubsection{Housing}

Next we examine housing characteristics. We find a negative significant relationship between respondents in the countryside and changing behaviors but this association becomes indistinguishable from zero as other controls are added. We find a robust negative association for having no access to open air and increased social distancing behavior. In our full control case, we find that respondents that live in homes without open air access are $12 \%$ less likely to increase social distancing behaviors. We find this to be an intuitive result. People who are more comfortable sheltering-in-place are more likely to do it. Policies aiming to slow the pandemic should take these factors into account as they suggest cramped and uncomfortable

\footnotetext{
${ }^{17}$ Oddly, we find a strong negative association between heart disease and increased social distancing, which may reflect that people with heart disease are generally unhealthy and thus less likely to engage in self-protective behaviors.
} 
housing can potentially undermine efforts to "flatten the curve." We find similar patterns for the two other outcome variables, but they lose significance in the final specification, where we add additional variables.

\subsubsection{Work Arrangements and Losses}

We also consider work arrangements and economic losses. In general we find fairly consistent results across all three of our outcome variables. People who transitioned into tele-working are more likely to change behaviors, increase social distancing, and increase hand washingmask wearing. This association ranges from roughly $9 \%-12 \%$ relative to somebody who continued to work. This effect is robust to the inclusion of other controls. We find similarlysized effect for those that stopped working or never worked but significance was retained with less consistency. This result is intuitive. People who can work from home are more likely to abide by stay-at-home orders. Factors related to work arrangements, which vary across sociodemographic groups, can determine the sustainability and effectiveness of policies aiming to prevent the spread of illness. We also find that realized household income losses have a significant positive association with each of these behaviors. After controlling for extreme lost income values, we find that for every $\$ 1,000$ lost a respondent is $1 \%-4 \%$ more likely to adjust to each of the behaviors we examined. People who have experienced these losses have already been harmed by the pandemic. As a result, they may be more careful than others and view contracting the disease as a higher risk. Another possibility is that these people have fewer monetary resources and may not have money to cover medical expenses if they were to contract the disease.

\subsubsection{Beliefs and Perceptions}

The final set of variables we examined were beliefs and perceptions about the pandemic. Reassuringly, we find a fairly consistent effect for beliefs in the effectiveness of social distancing across the three behaviors we included. These findings are strongest for the changed 
behaviors and increase social distancing variables. We find similar results but with weaker significance for increased hand washing-mask wearing. As we previewed earlier, we find a significant negative association between beliefs about the local infection rate and each of the three outcome variables. We discussed possible reasons why respondents may have reported these implausibly high beliefs earlier. Our findings are robust to removing this variable as well as using a dummy variable to control for extremely high beliefs. ${ }^{18}$ We also find some positive associations between perceived benefits from the pandemic and increases in our behaviors of interest. Less pollution and more family time were two that came out as significant and tended to retain significance as other controls were added. In Table 5, we present cross-tabulations of the survey data which indicate most of the people identifying these benefits belonged to higher income quintiles and were non-white.

One finding that surprised us was the negative association between beliefs about local infection rates and increases in self protecting behaviors. As discussed previously, the distribution of respondent beliefs about local infection rates has significant mass at the low and high end, which are difficult to reconcile with reality. In Figures A.3, A.4, and A.5 we present lowess smoother results for three behavioral outcomes of interest and this belief. In each case, people who reported an infection rate of $20 \%$ or fewer exhibit the expected response: a rise in perceived infection rates is associated with more protective behavior. Thus, negative coefficient estimates are driven by people with implausibly high perceptions of infection rates. This could reflect respondent confusion. It could also reflect a sort of fatalism, i.e., people believe infection rates are so high that they are bound to become infected, too, and thus don't bother to engage in protective behaviors. Fatalism is a well documented phenomenon in several fields, see e.g., Akesson et al. (2020), Ferrer and Klein (2015), Shapiro and Wu (2011), etc. ${ }^{19}$

\footnotetext{
${ }^{18}$ We defined the cutoff for "extremely high" as any belief above $20 \%$.

${ }^{19}$ Figures A.6, A.7, and A.8 present similar figures using the lpoly smoother.
} 


\subsection{Robustness checks}

We conducted a series of other robustness checks to these specifications. For example, rather than examining increases in social distancing or hand washing-mask wearing, we considered whether or not the respondent was doing these behaviors at all in the weeks following the start of the pandemic. Our main conclusions are unchanged, with the additional finding that pre-pandemic behavior has a very significant association with post-pandemic behavior. We also considered whether the behavior changes for people who had experienced some loss due to the pandemic were distinct from the pooled sample. In general we do not pick up many significant effects for these sub-samples. The associations that are captured are generally in line with the findings from the main analysis. We also ran our specifications for each state individually as well as for pooled groups of states. In general we either lose statistical significance or find patterns similar to our main results. These tables are available upon request.

\section{Conclusion}

While many of the questions raised and discussed in this paper focus on the here-and-now, the Covid-19 pandemic will eventually run its course. However, it would be shortsighted and naive to think that another virus, perhaps an even more damaging one, will not come about in the future. Indeed, many specialists believe that this virus will be cyclical, returning annually. If so, the questions we are addressing now will be important not only as we move through the current crisis, but also as we begin to prepare for the next one. Social scientists who study behavior - and the policies that affect it - must play a critical role in these efforts. One way is through the collection and analysis of new survey data, which shed light on what behavior can be expected of different segments of the population during a pandemic given heterogeneity in the incentives, constraints and circumstances people face. These data could be used not only to describe behavior, but also in more targeted research projects, such as: 
examining how information is transmitted and belief about the pandemic are formed and affect behavior, analyzing location-specific policy responses and their relative merit, and calibrating epidemiologically-grounded models relating variation in individual behavior to the spread of illness, among many others. 


\section{References}

Adams-Prassl, Abi, Teodora Boneva, Marta Golin, and Christopher Rauh (Apr. 2020a). Inequality in the Impact of the Coronavirus Shock: Evidence from Real Time Surveys. Working Paper 2018. Cambridge-INET.

- (May 2020b). The Impact of the Coronavirus Lockdown on Mental Health: Evidence from the US. Working Paper 2020-030. Human Capital and Economic Opportunity Working Group.

Akesson, Jesper, Sam Ashworth-Hayes, Robert Hahn, Robert D Metcalfe, and Itzhak Rasooly (May 2020). Fatalism, Beliefs, and Behaviors During the COVID-19 Pandemic. Working Paper 27245. National Bureau of Economic Research.

Alon, Titan M, Matthias Doepke, Jane Olmstead-Rumsey, and Michele Tertilt (Apr. 2020). The Impact of COVID-19 on Gender Equality. Working Paper 26947. National Bureau of Economic Research.

Barth, Daniel, Nicholas W Papageorge, and Kevin Thom (2020). "Genetic Endowments and Wealth Inequality". In: Journal of Political Economy 128.4, pp. 1474-1522.

Belot, Michele, Syngjoo Choi, Julian Jamison, Nicholas W Papageorge, Egon Tripodi, and Eline van den Broeck (May 2020). Six-country Survey on Covid-19. Discussion Paper 13230. IZA.

Borjas, George J (Apr. 2020). Demographic Determinants of Testing Incidence and COVID-19 Infections in New York City Neighborhoods. Working Paper 26952. National Bureau of Economic Research.

Cawley, John and Christopher J Ruhm (2011). "The Economics of Risky Health Behaviors". In: Handbook of Health Economics. Vol. 2. Elsevier, pp. 95-199.

Chan, Tat Y, Barton H Hamilton, and Nicholas W Papageorge (2016). "Health, Risky Behaviour and the Value of Medical Innovation for Infectious Disease". In: The Review of Economic Studies 83.4, pp. 1465-1510.

Coibion, Olivier, Yuriy Gorodnichenko, and Michael Weber (May 2020). The Cost of the COVID-19 Crisis: Lockdowns, Macroeconomic Expectations, and Consumer Spending. Working Paper 27141. National Bureau of Economic Research.

Cutler, David M., Adriana Lleras-Muney, and Tom Vogl (Apr. 2011). "Socioeconomic Status and Health: Dimensions and Mechanisms". In: The Oxford Handbook of Health Economics. Oxford University Press.

Delavande, Adeline, Michael Perry, and Robert J Willis (2006). Probabilistic Thinking and Social Security Claiming. Working Paper 129. Michigan Retirement Research Center.

DeLuca, Stephanie, Nicholas W Papageorge, and Emma Kalish (Apr. 2020). The Unequal Cost of Social Distancing. Available at https://coronavirus.jhu.edu/from-ourexperts/the-unequal-cost-of-social-distancing.

Fairlie, Robert W, Kenneth Couch, and Huanan Xu (May 2020). The Impacts of COVID-19 on Minority Unemployment: First Evidence from April 2020 CPS Microdata. Working Paper 27246. National Bureau of Economic Research.

Ferrer, Rebecca A and William MP Klein (2015). "Risk Perceptions and Health Behavior". In: Current Opinion in Psychology 5, pp. 85-89.

Lillard, Lee A and Robert J Willis (2001). Cognition and Wealth: The Importance of Probabilistic Thinking. Working Paper 7. Michigan Retirement Research Center. 
Manski, Charles F (1999). Identification Problems in the Social Sciences. Harvard University Press.

Mongey, Simon, Laura Pilossoph, and Alex Weinberg (May 2020). Which Workers Bear the Burden of Social Distancing Policies? Working Paper 27085. National Bureau of Economic Research.

Pampel, Fred C, Patrick M Krueger, and Justin T Denney (2010). "Socioeconomic Disparities in Health Behaviors". In: Annual Review of Sociology 36, pp. 349-370.

Papageorge, Nicholas W (2016). "Why Medical Innovation is Valuable: Health, Human Capital, and the Labor Market". In: Quantitative Economics 7.3, pp. 671-725.

Posner, Richard A and Tomas J. Philipson (1993). Private Choices and Public Health: The AIDS Epidemic in an Economic Perspective. Harvard University Press.

Shapiro, Joel and Stephen Wu (2011). "Fatalism and Savings". In: The Journal of Socio-Economics 40.5, pp. 645-651.

Viner, Russell M, Simon J Russell, Helen Croker, Jessica Packer, Joseph Ward, Claire Stansfield, Oliver Mytton, Chris Bonell, and Robert Booy (2020). "School Closure and Management Practices During Coronavirus Outbreaks Including COVID-19: A Rapid Systematic Review". In: The Lancet Child 85 Adolescent Health.

Wozniak, Abigail (May 2020). Disparities and Mitigation Behavior During COVID-19. Institute Working Paper 32. Opportunity and Inclusive Inclusive Growth Institute: Federal Reserve Bank of Minneapolis.

Yancy, Clyde W. (May 2020). "COVID-19 and African Americans". In: Journal of the American Medical Association 323.19, pp. 1891-1892. 


\section{Figures}

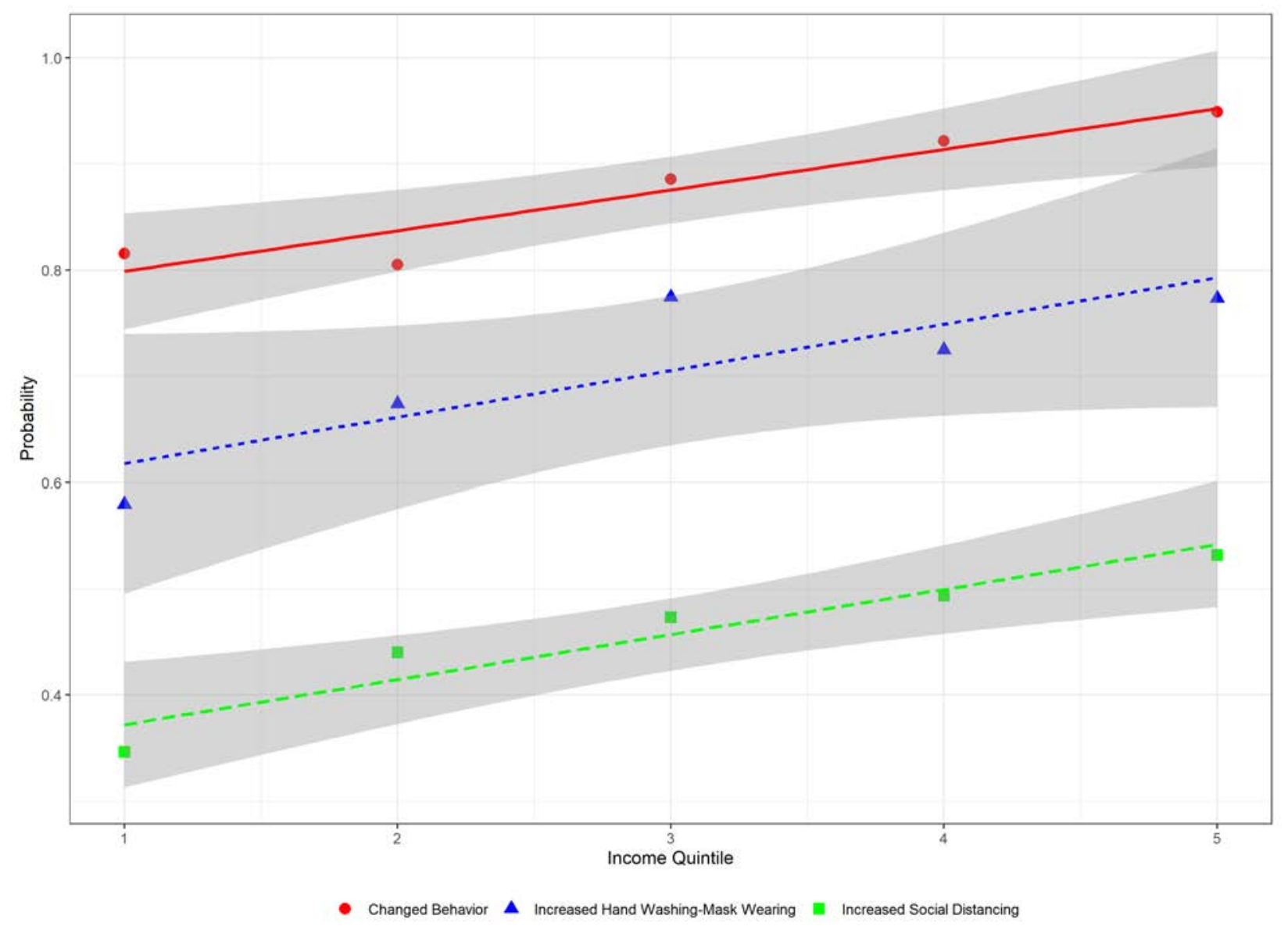

Figure 1: Probability of Actions by Income Quintile: Proportion of respondents within an income quintile that changed behaviors, increased social distancing, or increased handwashingmask wearing. 

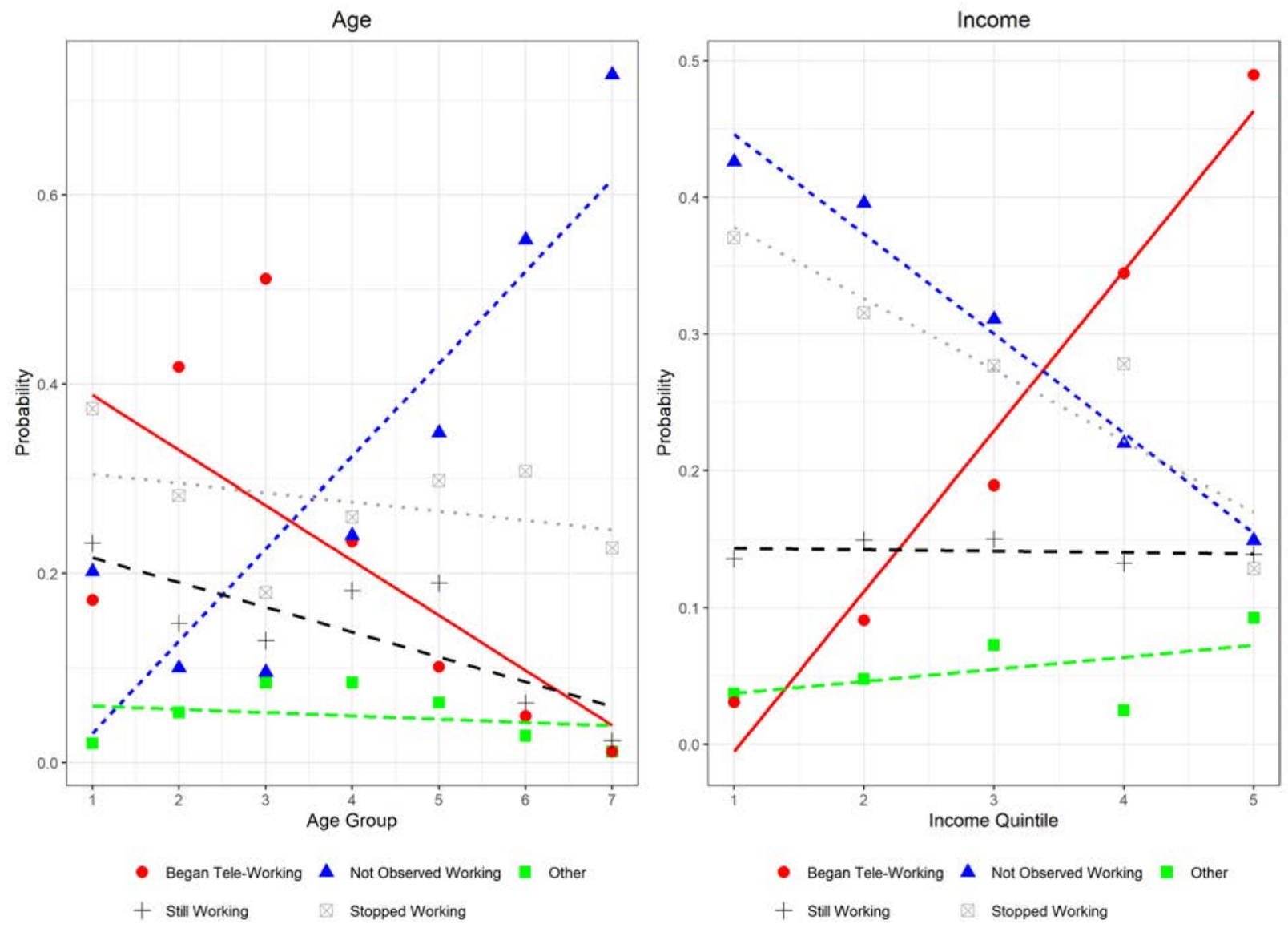

Figure 2: Probability of Work Arrangement by Age Group and Income Quintile: Proportion of respondents within an age group or income quintile that are classified into our work arrangements variable. 


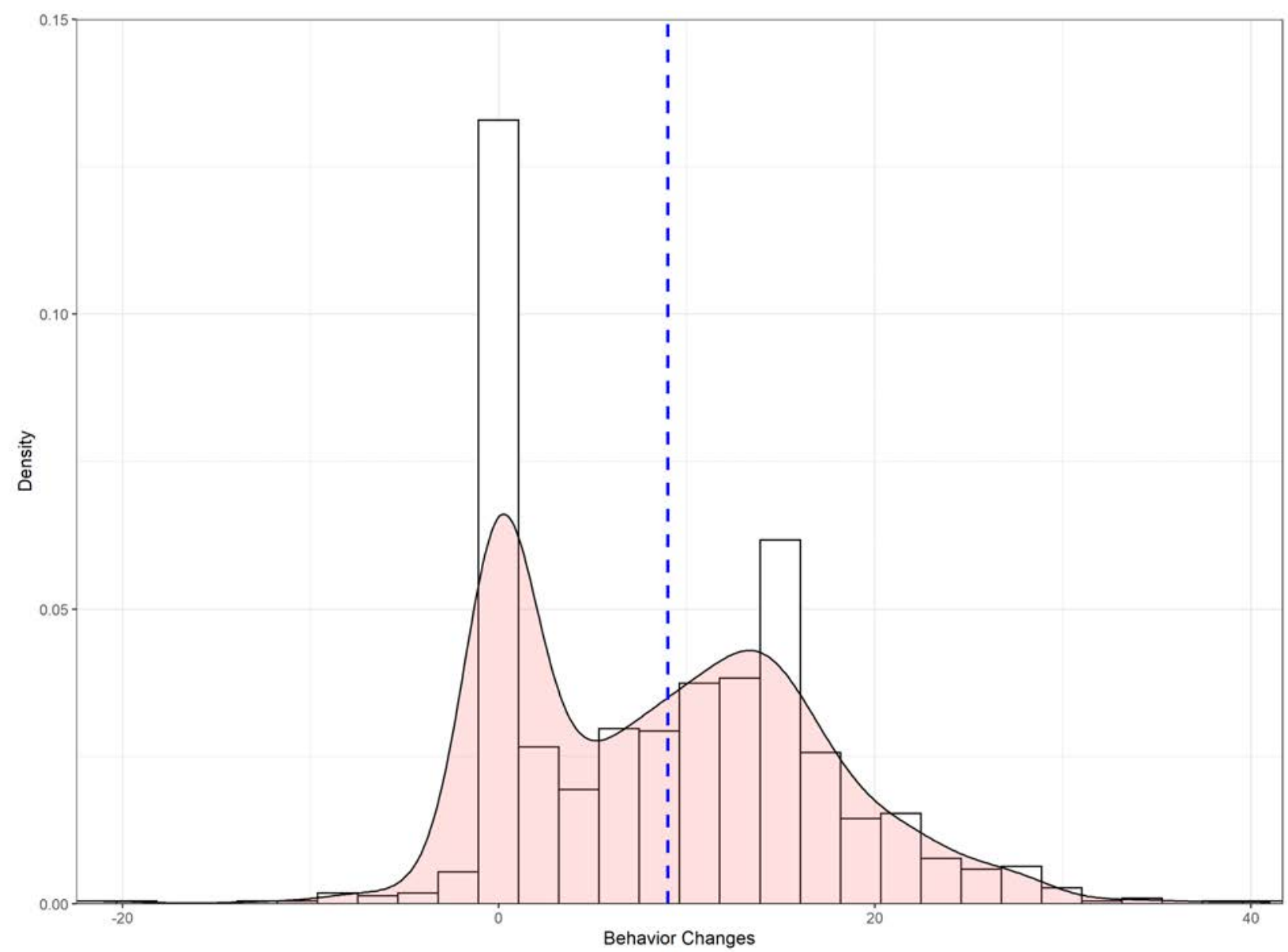

Figure 3: Distribution of Behavior Changes: Distribution of behavior changes from before the pandemic to a few weeks after the pandemic started. Changes are normalized such that self-protecting changes are positive and reductions in these behaviors are negative. 


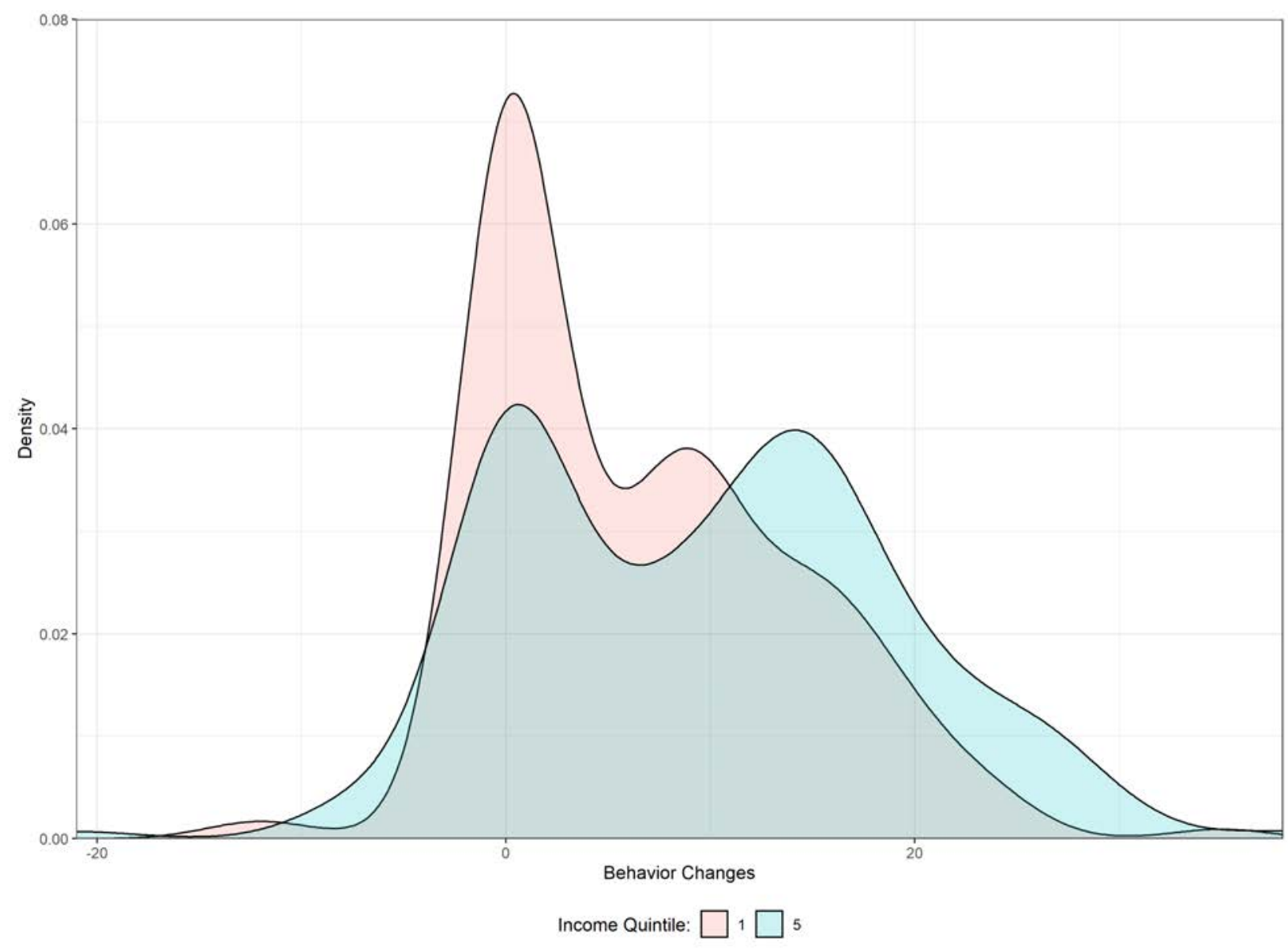

Figure 4: Distribution of Behavior Changes by Income Quintile: Distribution of behavior changes by income quintile from before the pandemic to a few weeks after the pandemic started. Changes are normalized such that self-protecting changes are positive and reductions in these behaviors are negative. 

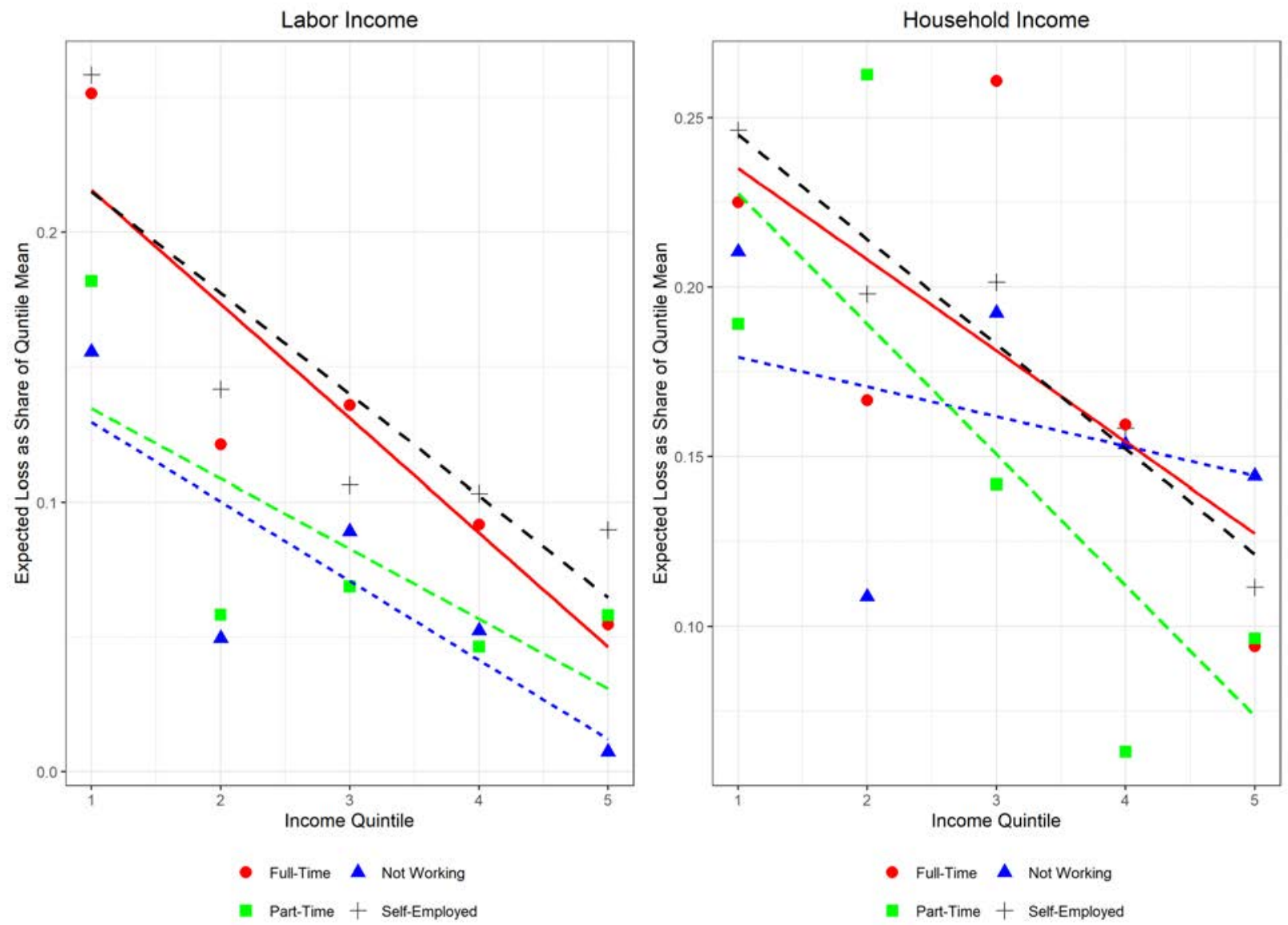

Figure 5: Expected Income Losses by Income and Labor Status: Expected labor and household income losses across income quintiles. Income losses are normalized by the mean income of the respondent's quintile. 

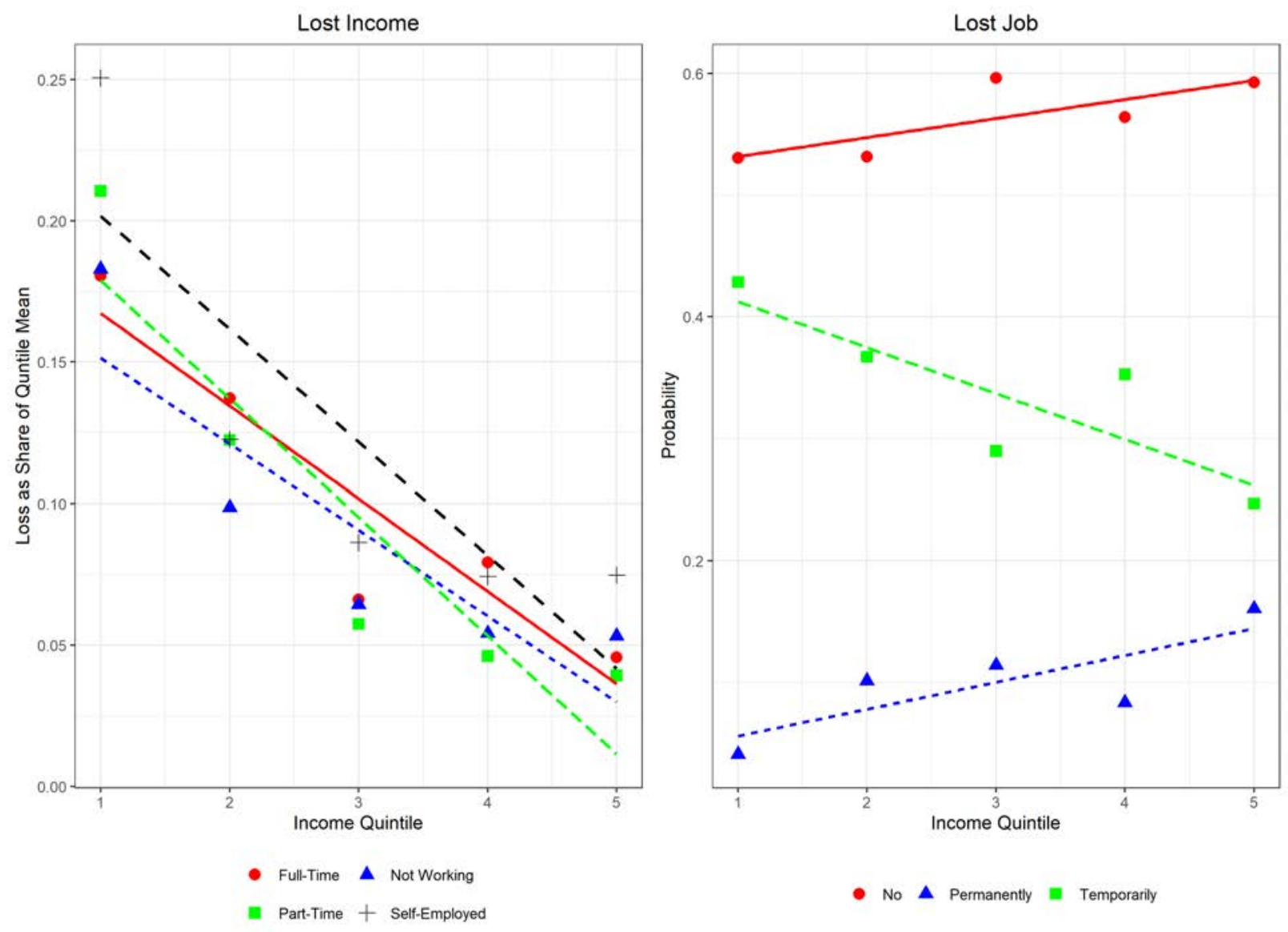

Figure 6: Realized Losses by Income: Realized income and job losses by income quintile. Income losses are normalized by the mean income of the respondent's quintile. Job losses are proportions of each type of labor transition within an income quintile. 

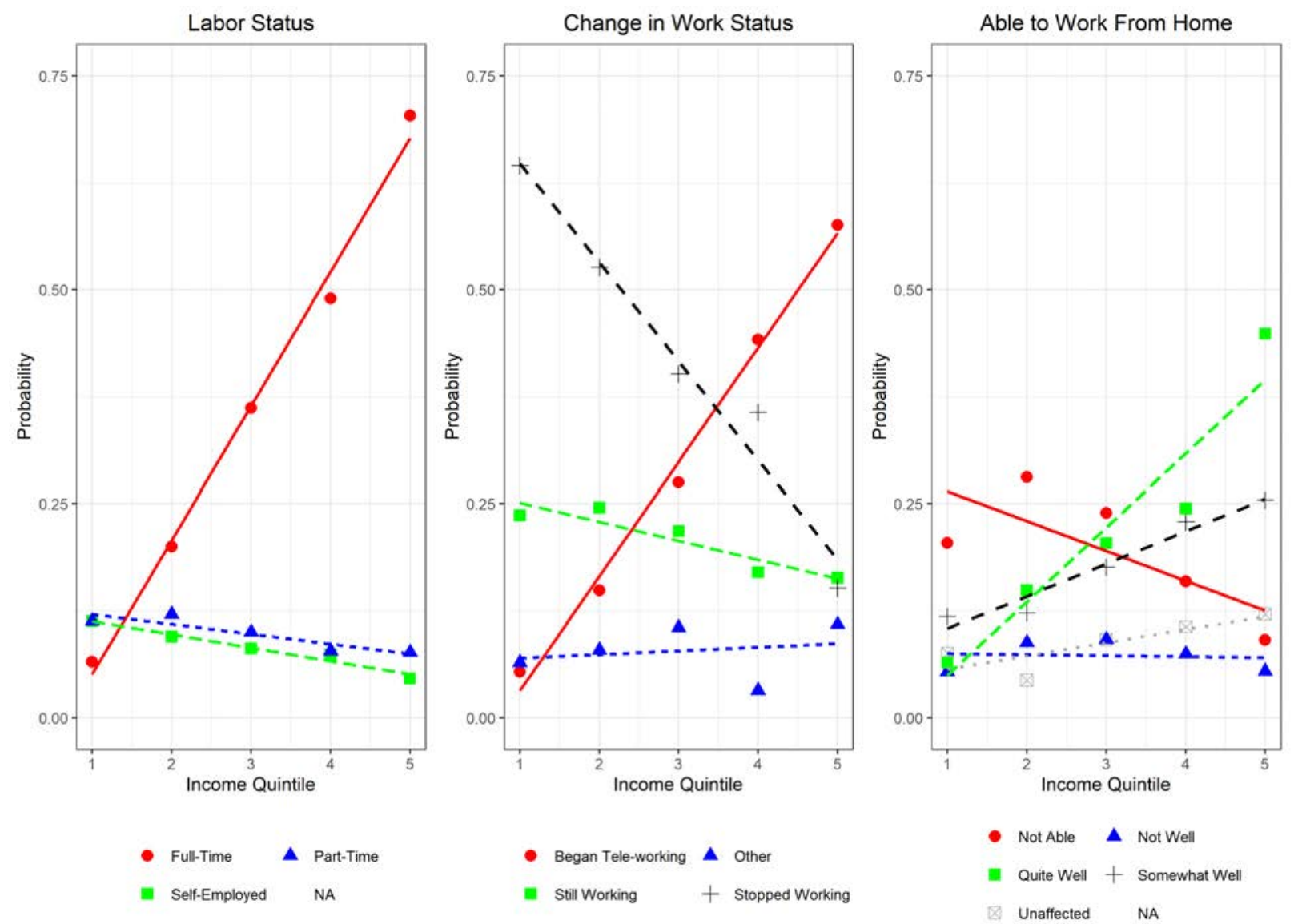

Figure 7: Probability of Labor Characteristic by Income Quintile: Proportion of respondents within an income quintile with various labor characteristics. 


\section{Tables}

Table 1: Summary Statistics

\begin{tabular}{|c|c|c|}
\hline Variable & Prob & $\mathrm{N}$ \\
\hline \multicolumn{3}{|l|}{ Socio-Demographics: } \\
\hline Non-White & 0.15 & 1006 \\
\hline Male & 0.44 & 1006 \\
\hline New York-California & 0.54 & 1006 \\
\hline Elderly & 0.39 & 1006 \\
\hline \multicolumn{3}{|l|}{ Health: } \\
\hline Pre-existing Condition & 0.45 & 1006 \\
\hline \multicolumn{3}{|l|}{ Housing: } \\
\hline Urban & 0.41 & 1006 \\
\hline Home w/o Open Air Access & 0.15 & 1006 \\
\hline Elderly Exposure & 0.46 & 1006 \\
\hline \multicolumn{3}{|l|}{ Work Arrangements and Losses: } \\
\hline Mean Income Quintile & 3.11 & 1006 \\
\hline Working & 0.7 & 990 \\
\hline Full-Time - Working & 0.54 & 701 \\
\hline Part-Time - Working & 0.14 & 701 \\
\hline Can Work From Home - Working & 0.82 & 701 \\
\hline Work Change: No Longer Working - Working & 0.38 & 701 \\
\hline Work Change: Tele-Working — Working & 0.34 & 701 \\
\hline Work Change: No Change - Working & 0.2 & 701 \\
\hline Mean Lost HH. Income $(\$ 1,000)$ & 0.77 & 475 \\
\hline \multicolumn{3}{|l|}{ Beliefs and Perceptions: } \\
\hline Mean Belief in Effectiveness of SD & 3.99 & 1006 \\
\hline Local Infection Rate & 0.24 & 971 \\
\hline Benefits from Pandemic & 0.84 & 1006 \\
\hline \multicolumn{3}{|l|}{ Outcomes: } \\
\hline Changed Behavior & 0.88 & 1006 \\
\hline Increased SD & 0.46 & 967 \\
\hline Increased Hand Washing-Mask Wearing & 0.71 & 933 \\
\hline $\mathrm{N}$ & & 1006 \\
\hline
\end{tabular}

Values represent the proportion of respondents with the listed characteristic for the entire US sample. 
Table 2: Differences by Characteristic for Low Income

\begin{tabular}{lcc}
\hline Characteristic & Difference of Means & p-value \\
\hline Not White - White & 0.14 & 0.00 \\
Not Male - Male & 0.19 & 0.00 \\
No Pre-existing Condition - Pre-existing Condition & 0.03 & 0.40 \\
No Elderly Exposure - Elderly Exposure & -0.05 & 0.11 \\
Not Working - Working & 0.2 & 0.00 \\
Not Full-Time - Full-Time - Working & 0.36 & 0.00 \\
Not Part-Time - Part-Time - Working & -0.15 & 0.00 \\
No Work From Home - Work From Home - Working & 0.11 & 0.01 \\
Not Still Working - Still Working - Working & -0.08 & 0.07 \\
Not Stopped Working - Stopped Working - Working & -0.24 & 0.00 \\
Not Tele-Working - Tele-Working - Working & 0.31 & 0.00 \\
Above Med. Belief in SD - Below Med. Belief in SD & 0.06 & 0.10 \\
N & 1006 & $\cdot$ \\
\hline
\end{tabular}

Values are the results from difference of means tests for the listed characteristics. The calculated means are for the proportion of people that are low income.

Table 3: Differences by Characteristic for Increased Social Distancing Behavior

\begin{tabular}{lcc}
\hline Characteristic & Difference of Means & p-value \\
\hline Non-White - White & -0.08 & 0.07 \\
Not Male - Male & 0.16 & 0.00 \\
No Pre-existing Condition - Pre-existing Condition & 0.02 & 0.58 \\
No Elderly Exposure - Elderly Exposure & -0.05 & 0.14 \\
Not Working - Working & 0.07 & 0.06 \\
Not Full-Time - Full-Time - Working & 0.02 & 0.64 \\
Not Part-Time - Part-Time - Working & -0.04 & 0.46 \\
Cannot Work From Home - Can Work From Home - Working & 0.01 & 0.92 \\
Not Still Working - Still Working - Working & 0.16 & 0.00 \\
Not Stopped Working - Stopped Working - Working & -0.01 & 0.82 \\
Not Tele-Working - Tele-Working - Working & -0.07 & 0.07 \\
Below Med. Belief in SD - Above Med. Belief in SD & -0.24 & 0.00 \\
N & 967 &. \\
\hline
\end{tabular}

Values are the results from difference of means tests for the listed characteristics. The calculated means are for the proportion of people that increased social distancing behaviors. 
Table 4: Summary of Factors Associated with Self-Protective Behaviors

\begin{tabular}{llccc}
\hline \multicolumn{1}{c}{ Variable } & Metric & CB & SD & WM \\
\hline \multirow{2}{*}{ Income } & Significant & $\checkmark$ & $\checkmark$ & $\checkmark$ \\
& Sign & + & + & + \\
\hline \multirow{2}{*}{ Not Working } & Significant & $\checkmark$ & $\boldsymbol{x}$ & $\checkmark$ \\
& Sign & + & NA & + \\
\hline \multirow{2}{*}{ Tele-Working } & Significant & $\checkmark$ & $\checkmark$ & $\checkmark$ \\
& Sign & + & + & + \\
\hline \multirow{2}{*}{ Not Working Pre-Covid } & Significant & $\boldsymbol{x}$ & $\checkmark$ & $\boldsymbol{x}$ \\
& Sign & $\mathrm{NA}$ & + & $\mathrm{NA}$ \\
\hline \multirow{2}{*}{ Lost Income } & Significant & $\checkmark$ & $\checkmark$ & $\checkmark$ \\
& Sign & + & + & + \\
\hline \multirow{2}{*}{ Effectiveness of SD } & Significant & $\checkmark$ & $\checkmark$ & $\checkmark$ \\
& Sign & + & + & + \\
\hline \multirow{2}{*}{ Area Infection Rate } & Significant & $\boldsymbol{x}$ & $\checkmark$ & $\checkmark$ \\
& Sign & $\mathrm{NA}$ & - & - \\
\hline \multirow{2}{*}{ Benefits } & Significant & $\boldsymbol{V}$ & $\checkmark$ & $\checkmark$ \\
& Sign & + & + & + \\
\hline
\end{tabular}

This table summarizes the core findings from linear probability models examining the association between socio-demographic characteristics and three different self-protective behaviors. Detailed tables with coefficient estimates, standard errors, significance levels, and other controls can be found in the Appendix. 
Table 5: Benefits of Pandemic by Income

\begin{tabular}{lcccccccc}
\hline & \multicolumn{3}{c}{ More Family Time } & & \multicolumn{3}{c}{ Less Pollution } \\
\cline { 2 - 4 } \cline { 7 - 8 } Income Quintile & Not Selected & Selected & Total & & Not Selected & Selected & Total \\
\hline First & 0.64 & 0.36 & 168 & & 0.64 & 0.36 & 168 \\
Second & 0.67 & 0.33 & 190 & & 0.61 & 0.39 & 190 \\
Third & 0.59 & 0.41 & 210 & & 0.56 & 0.44 & 210 \\
Fourth & 0.53 & 0.47 & 243 & & 0.59 & 0.41 & 243 \\
Fifth & 0.43 & 0.57 & 196 & & 0.61 & 0.39 & 196 \\
\hline
\end{tabular}

Cross tabulation of US sample for two perceived benefits of the pandemic by income quintiles. 


\section{A Additional Figures and Tables}

\section{A.1 Figures}

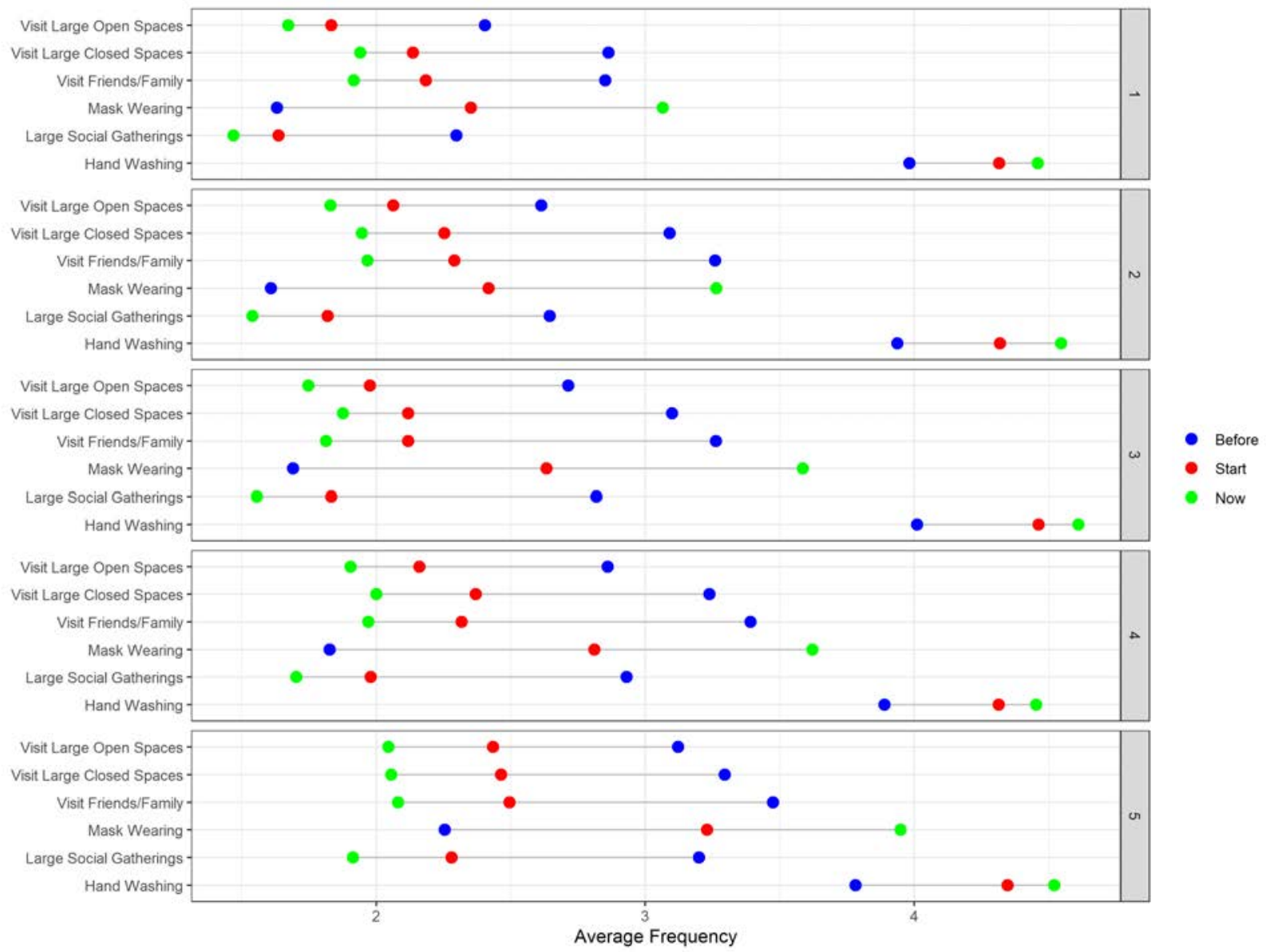

Figure A.1: Average Frequency of Select Behaviors by Income Quintile and Time Period: These tabulations are the average frequency respondents within an income group reported doing each listed activity. Frequencies ranged from 1 (Never) to 5 (Always). These are calculated for the time period before the pandemic, at the start of the pandemic, and a few weeks after the pandemic. 


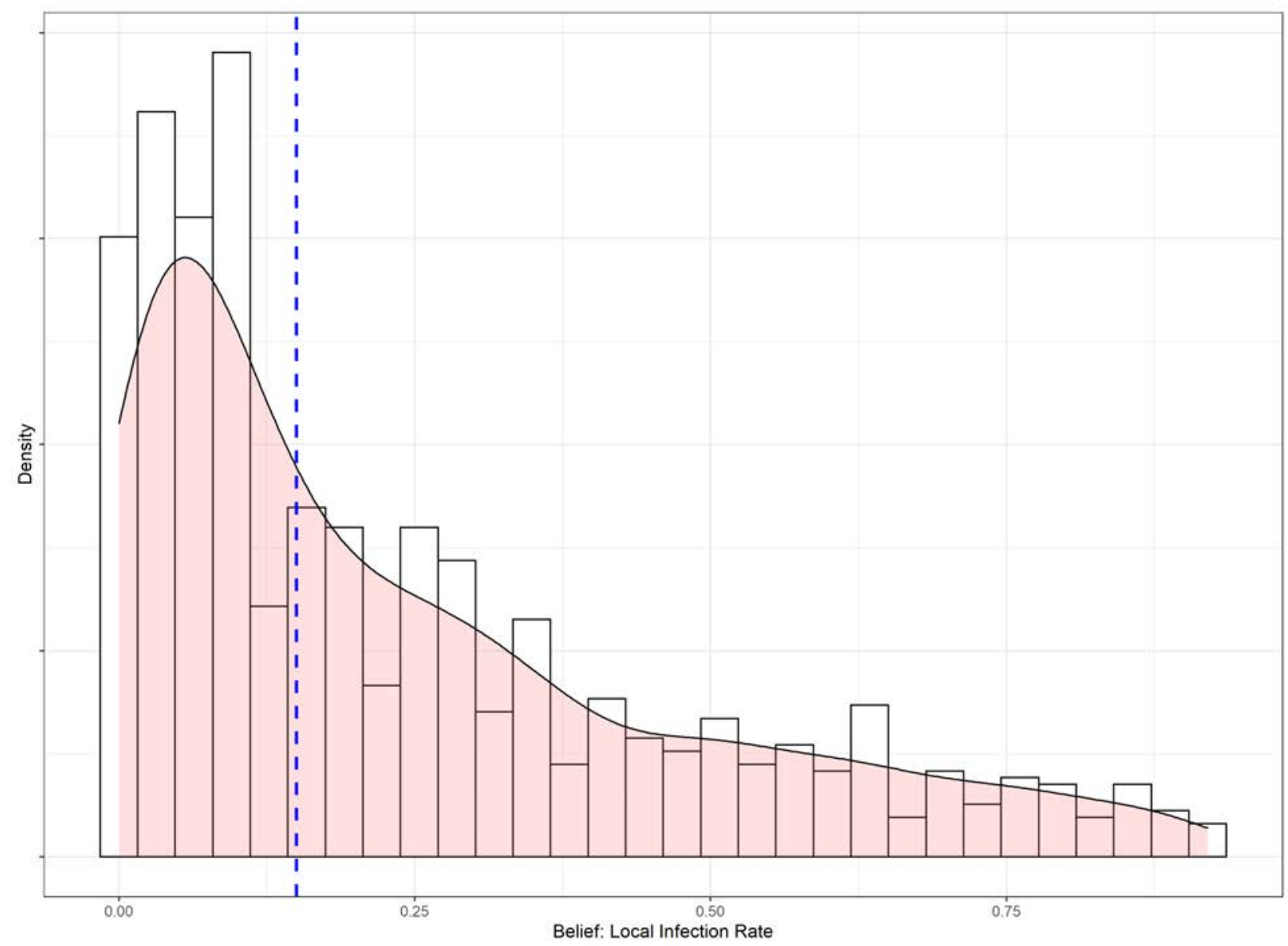

Figure A.2: Distribution of Beliefs About Local Infection Rates: Distribution of the reported beliefs of respondents about the rate of infections within their local community. 


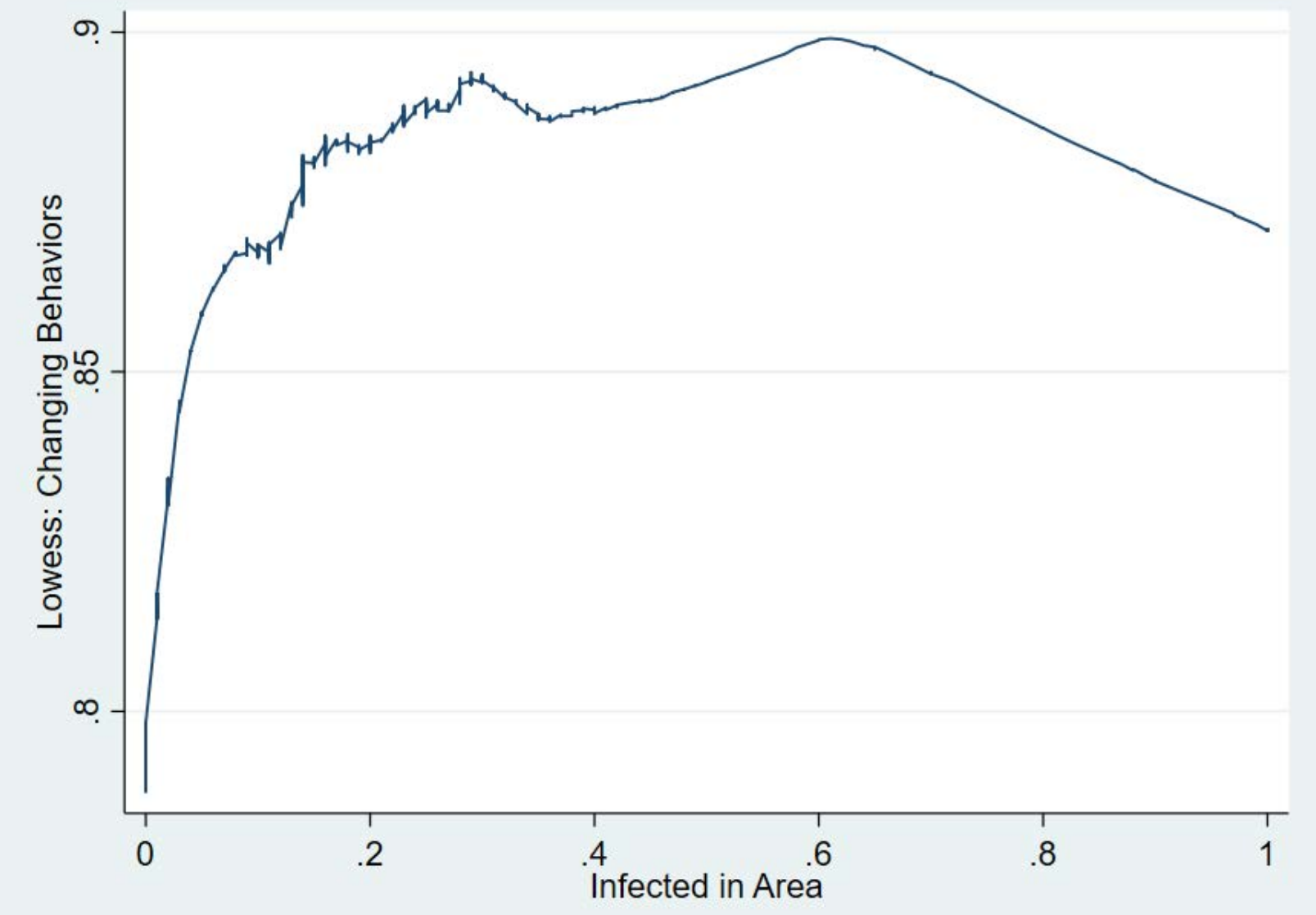

Figure A.3: Lowess Smoother Changed Behaviors: Lowess smoother applied to the binary changed behaviors outcome to beliefs about the local infection rate. 


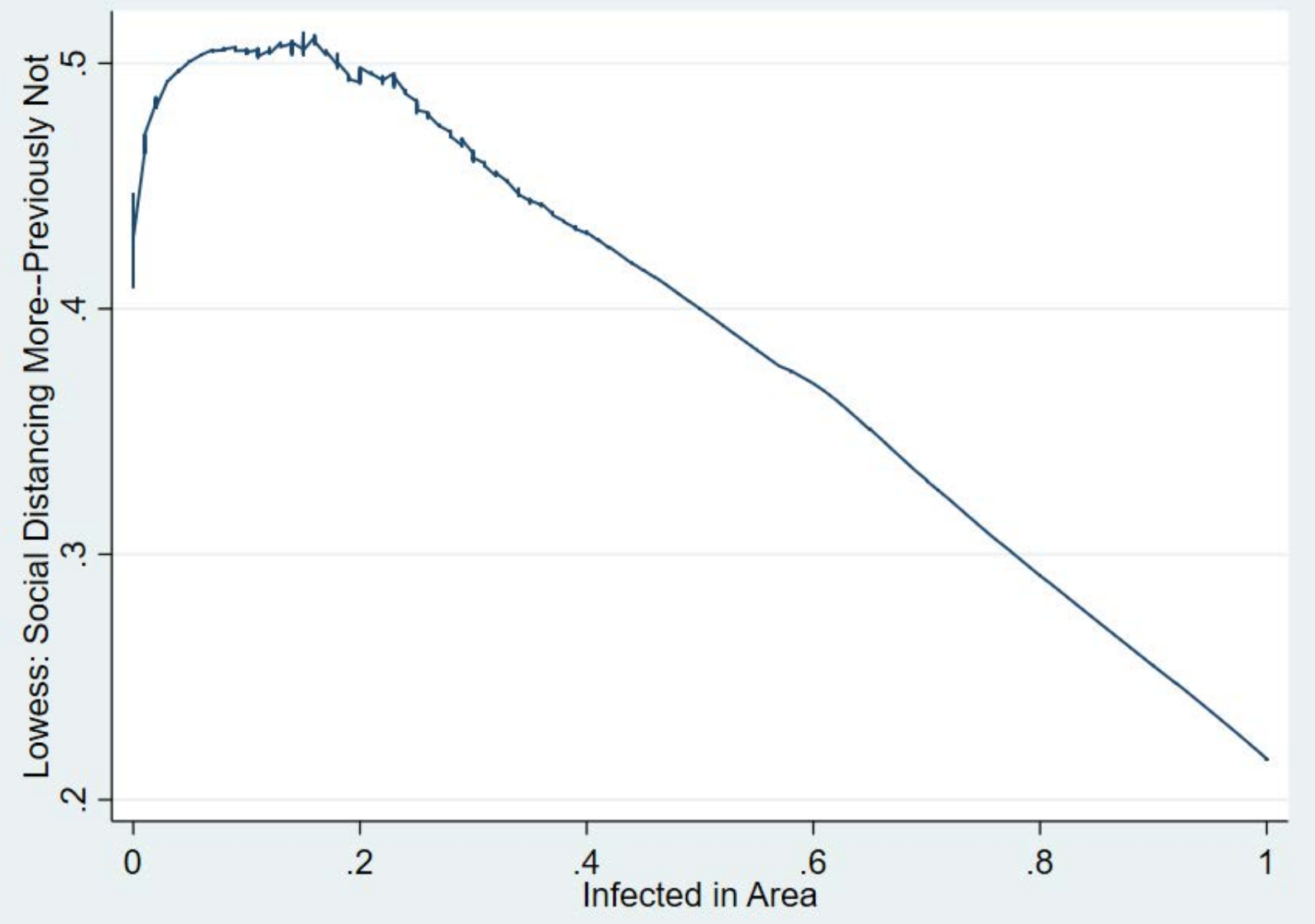

Figure A.4: Lowess Smoother Increased Social Distancing: Lowess smoother applied to the binary increased social distancing variable to beliefs about the local infection rate. Increased social distancing is defined as an above median increase in self protective behaviors (e.g., visiting public spaces, visiting friends and family, etc.) from before the pandemic to a few weeks after it started. 


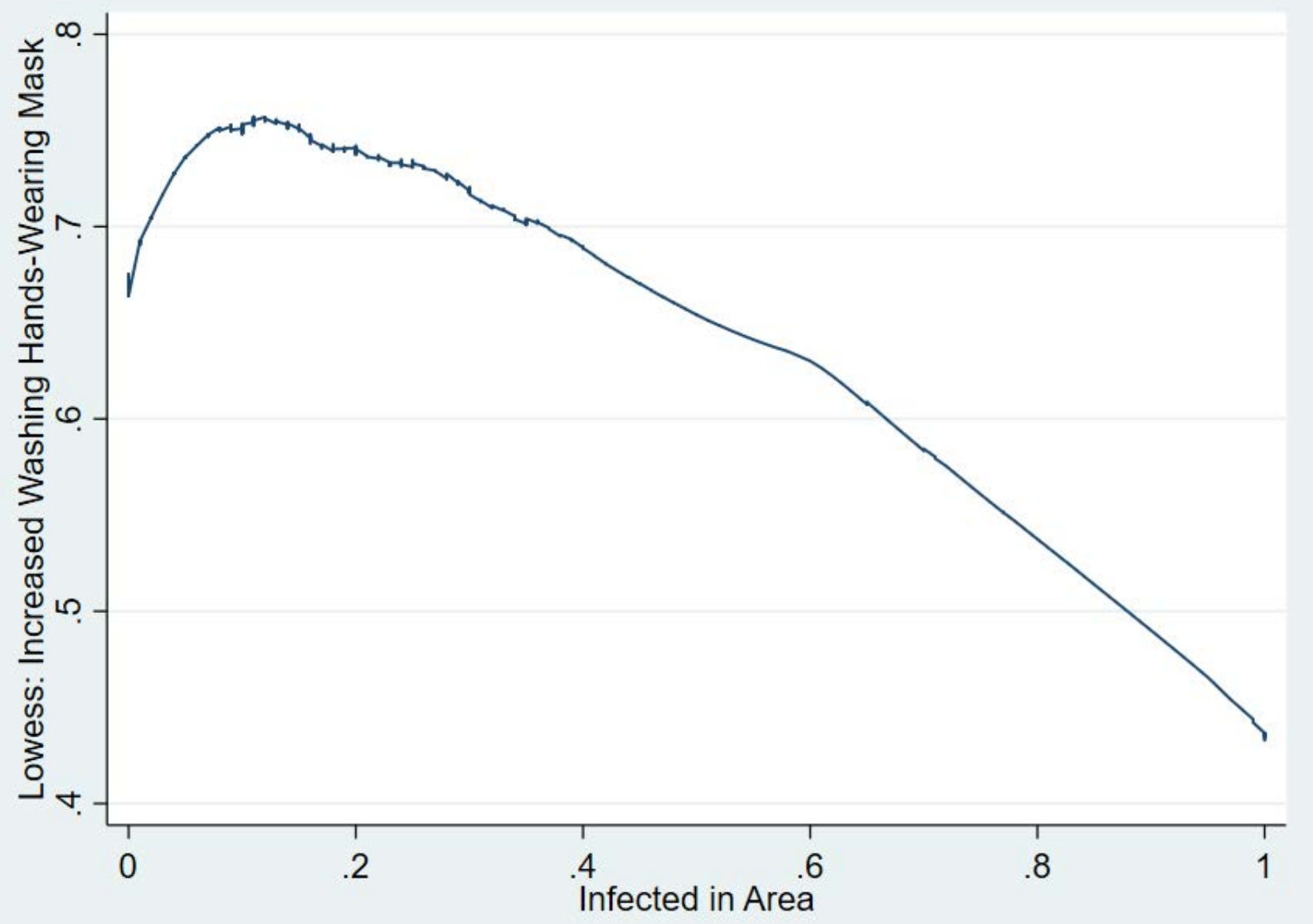

Figure A.5: Lowess Smoother Increased Hand Washing-Mask Wearing: Lowess smoother applied to the binary increased hand washing-mask wearing variable to beliefs about the local infection rate. Increased hand washing-mask wearing is defined as an above median increase in hand washing or mask wearing behavior from before the pandemic to a few weeks after it started. 


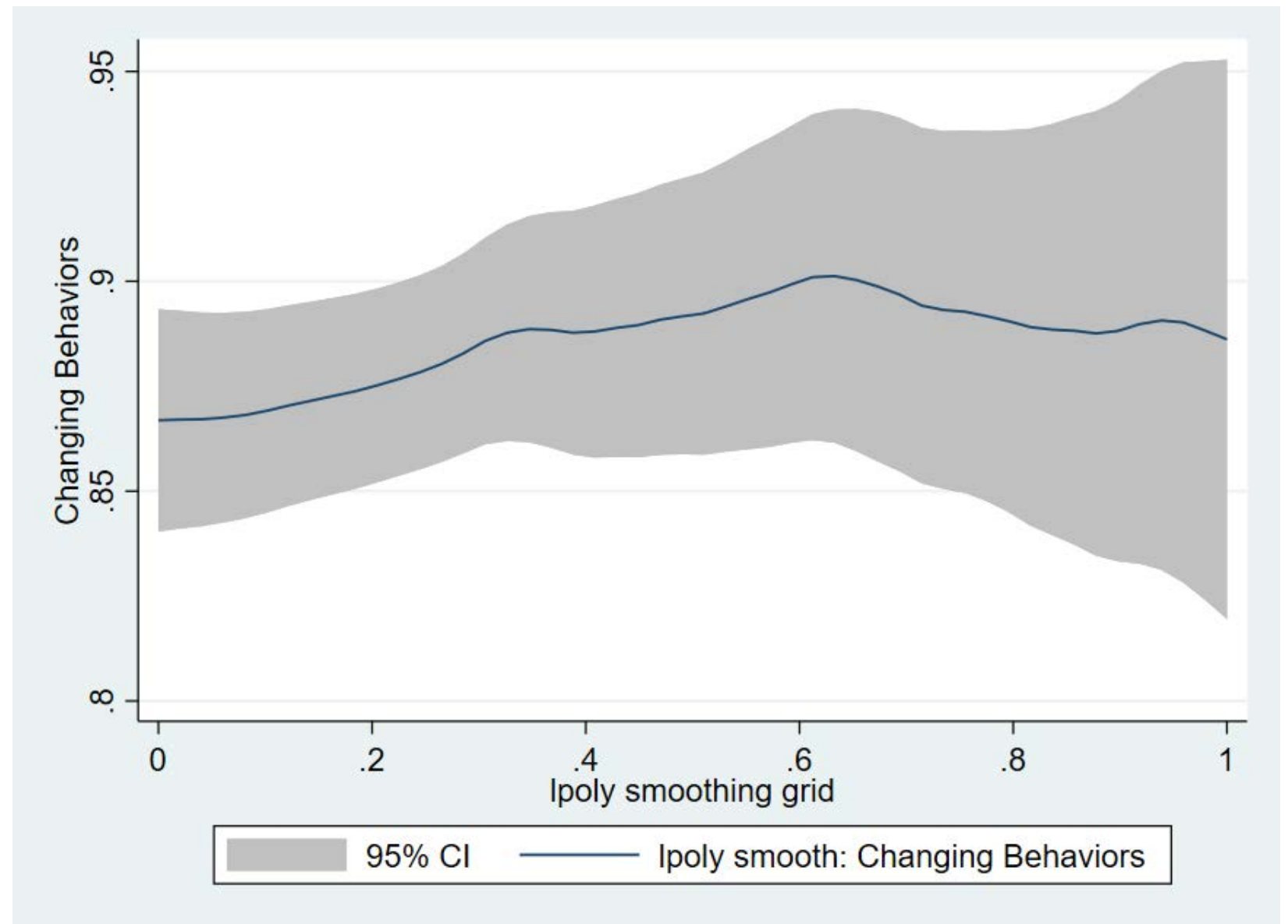

Figure A.6: Lpolyci Smoother Changed Behaviors: Lpolyci smoother applied to the binary changed behaviors outcome to beliefs about the local infection rate. 


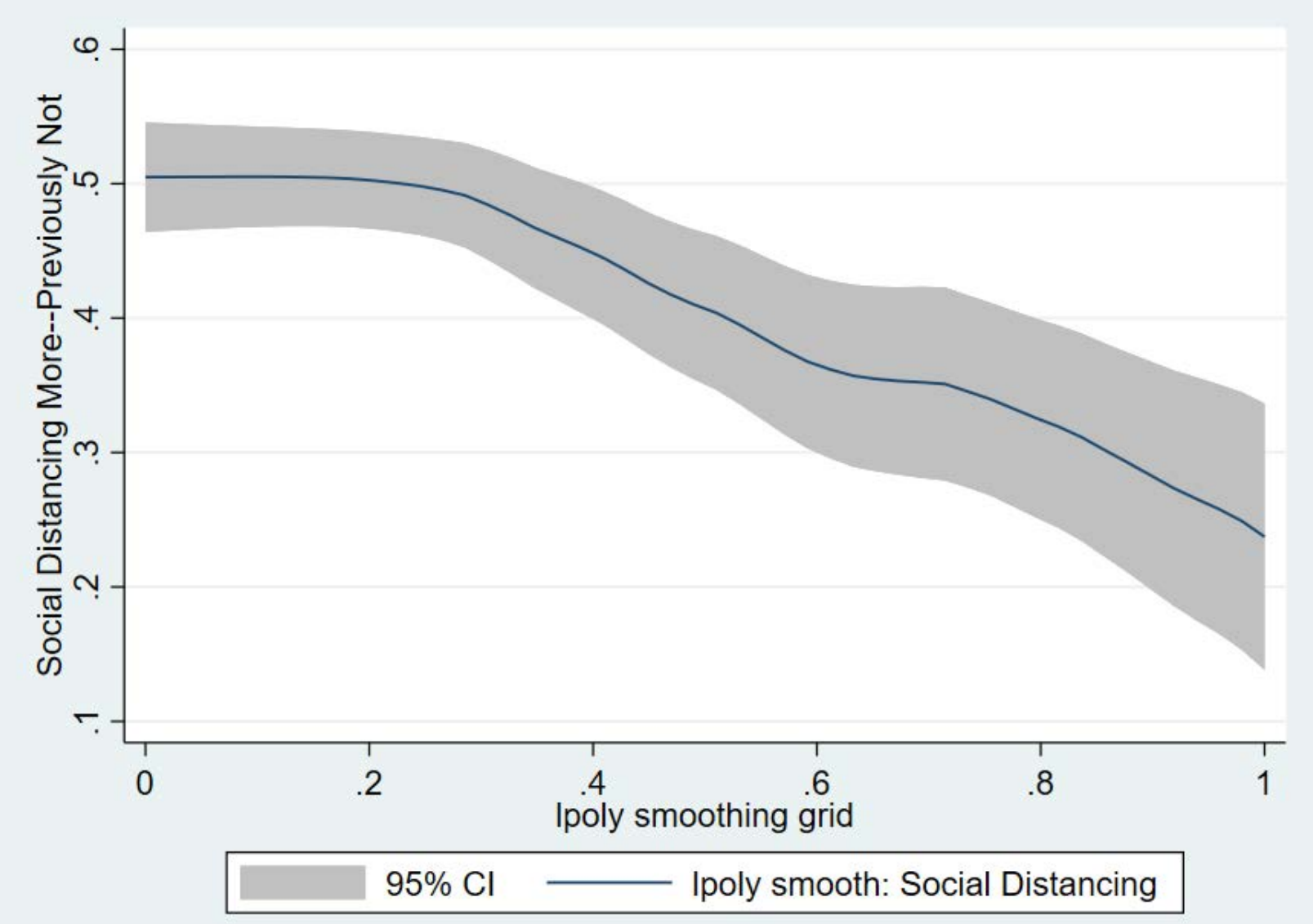

Figure A.7: Lpolyci Smoother Increased Social Distancing: Lpolyci smoother applied to the binary increased social distancing outcome to beliefs about the local infection rate. Increased social distancing is defined as an above median increase in self protective behaviors (e.g., visiting public spaces, visiting friends and family, etc.) from before the pandemic to a few weeks after it started. 


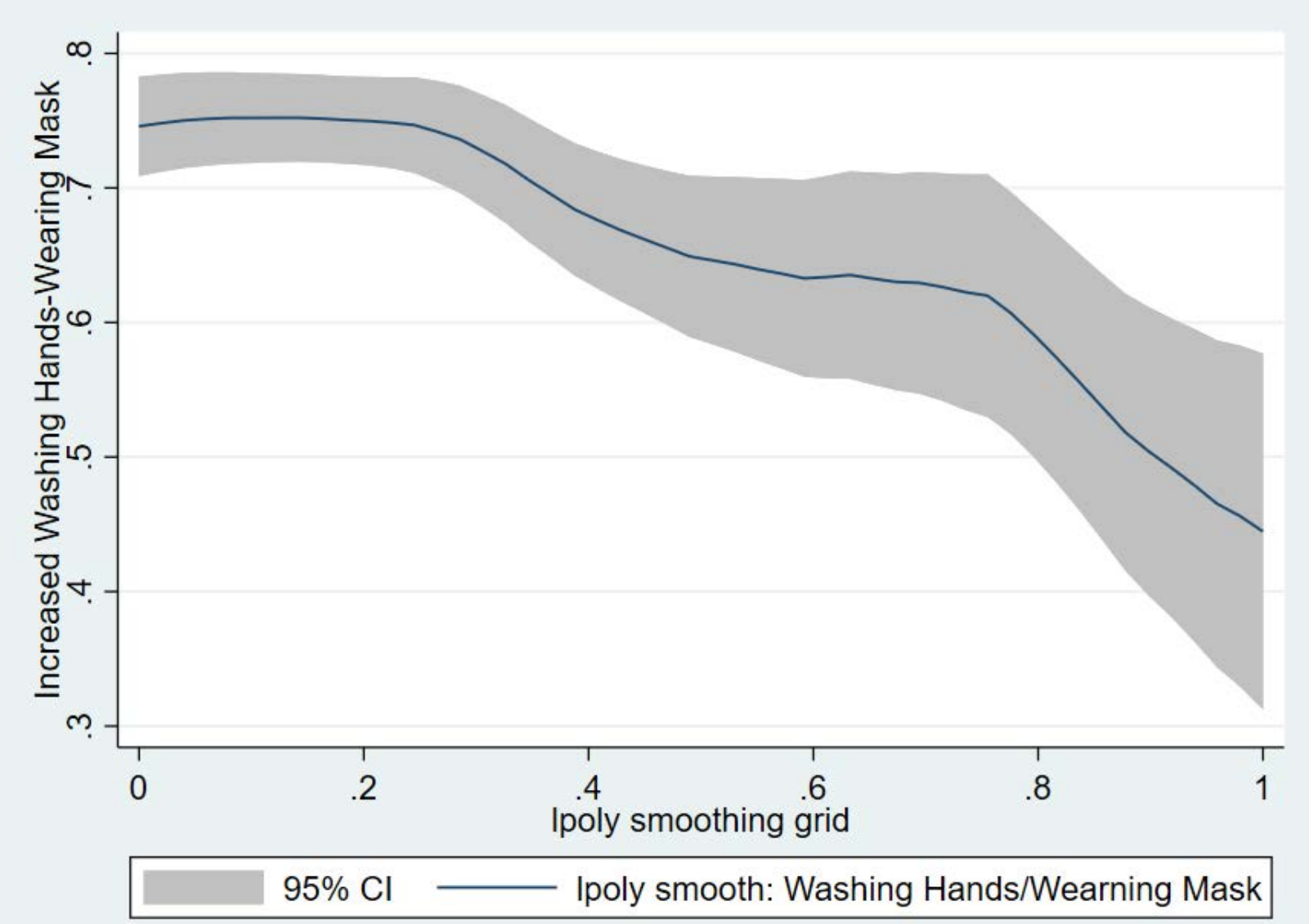

Figure A.8: Lpolyci Smoother Increased Hand Washing-Mask Wearing: Lpolyci smoother applied to the binary increased hand washing-mask wearing outcome to beliefs about the local infection rate. Increased hand washing-mask wearing is defined as an above median increase in hand washing or mask wearing behavior from before the pandemic to a few weeks after it started. 


\section{A.2 Tables}

\section{A.2.1 Cross Tabulations}

Table A.1: Pre-Existing Health Conditions by Income

\begin{tabular}{lcccc}
\hline Income & Diabetes & High Blood Pressure & Heart Disease & Asthma \\
\hline First quintile & 0.14 & 0.3 & 0.06 & 0.13 \\
Second quintile & 0.14 & 0.32 & 0.05 & 0.12 \\
Third quintile & 0.19 & 0.32 & 0.05 & 0.14 \\
Fourth quintile & 0.16 & 0.28 & 0.05 & 0.15 \\
Fifth quintile & 0.25 & 0.21 & 0.05 & 0.14 \\
\hline
\end{tabular}

Values are share of respondents within each income quintile that reported having the listed pre-existing health condition. Note respondents may have multiple conditions.

Table A.2: Current Living Area by Income

\begin{tabular}{lccccc}
\hline Current Living Area & First & Second & Third & Fourth & Fifth \\
\hline Urban & 0.41 & 0.33 & 0.29 & 0.41 & 0.62 \\
Semi-urban / residential & 0.41 & 0.52 & 0.6 & 0.49 & 0.35 \\
Countryside & 0.18 & 0.15 & 0.11 & 0.1 & 0.03 \\
Total & 168 & 190 & 210 & 243 & 196 \\
\hline
\end{tabular}

Cross tabulation of US sample for current living area by income quintiles. 
Table A.3: Home Characteristics by Income

\begin{tabular}{lccccc}
\hline Variable & First & Second & Third & Fourth & Fifth \\
\hline Current Home: & & & & & \\
House & 0.43 & 0.56 & 0.63 & 0.78 & 0.77 \\
Apartment & 0.39 & 0.29 & 0.24 & 0.15 & 0.18 \\
Condominium & 0.03 & 0.07 & 0.07 & 0.04 & 0.05 \\
Trailer & 0.1 & 0.07 & 0.04 & 0.01 & NA \\
Shelter & 0.02 & NA & NA & NA & NA \\
Other & 0.03 & 0.02 & 0.01 & 0.02 & 0.01 \\
Total & 168 & 190 & 210 & 243 & 196 \\
No Open Air & Access: & & & & \\
Not selected & 0.67 & 0.83 & 0.88 & 0.92 & 0.9 \\
Selected & 0.33 & 0.17 & 0.12 & 0.08 & 0.1 \\
Total & 168 & 190 & 210 & 243 & 196 \\
\hline
\end{tabular}

Cross tabulation of US sample for home characteristics by race.

Table A.4: Belief in Social Distancing by Income

\begin{tabular}{lccccc}
\hline Belief in Social Distancing & First & Second & Third & Fourth & Fifth \\
\hline Not effective at all & 0.03 & 0.04 & 0.03 & 0.02 & 0.03 \\
Slightly effective & 0.1 & 0.11 & 0.07 & 0.06 & 0.04 \\
Moderately effective & 0.17 & 0.16 & 0.17 & 0.19 & 0.15 \\
Very effective & 0.31 & 0.32 & 0.35 & 0.35 & 0.39 \\
Extremely effective & 0.39 & 0.38 & 0.38 & 0.38 & 0.39 \\
Total & 168 & 190 & 210 & 243 & 196 \\
\hline
\end{tabular}

Cross tabulation of US sample for belief in social distancing by income quintiles.

\section{A.2.2 Linear Probability Models}

Table A.5: Factors Associated with Changing Behaviors

\begin{tabular}{lccccccc}
\hline \hline & $(1)$ & $(2)$ & $(3)$ & $(4)$ & $(5)$ & $(6)$ & $(7)$ \\
\hline Income: & & & & & & & \\
Second quintile & -0.00 & -0.00 & -0.01 & -0.01 & -0.01 & 0.00 & -0.00 \\
& $(0.04)$ & $(0.04)$ & $(0.04)$ & $(0.04)$ & $(0.04)$ & $(0.04)$ & $(0.04)$ \\
Third quintile & $0.09^{* *}$ & $0.09^{* *}$ & $0.09^{* *}$ & $0.08^{* *}$ & $0.07^{*}$ & $0.08^{* *}$ & $0.07^{*}$ \\
& $(0.04)$ & $(0.04)$ & $(0.04)$ & $(0.04)$ & $(0.04)$ & $(0.04)$ & $(0.04)$ \\
\hline
\end{tabular}




\begin{tabular}{|c|c|c|c|c|c|c|c|}
\hline Fourth quintile & $\begin{array}{c}0.11^{* * *} \\
(0.04)\end{array}$ & $\begin{array}{c}0.12^{* * *} \\
(0.04)\end{array}$ & $\begin{array}{c}0.11^{* * *} \\
(0.04)\end{array}$ & $\begin{array}{c}0.10^{* * *} \\
(0.04)\end{array}$ & $\begin{array}{c}0.09^{* * *} \\
(0.04)\end{array}$ & $\begin{array}{c}0.10^{* * *} \\
(0.04)\end{array}$ & $\begin{array}{c}0.09^{* *} \\
(0.04)\end{array}$ \\
\hline Fifth quintile & $\begin{array}{c}0.14^{* * *} \\
(0.04)\end{array}$ & $\begin{array}{c}0.15^{* * *} \\
(0.04)\end{array}$ & $\begin{array}{c}0.15^{* * *} \\
(0.04)\end{array}$ & $\begin{array}{c}0.12^{* * *} \\
(0.04)\end{array}$ & $\begin{array}{c}0.11^{* * *} \\
(0.04)\end{array}$ & $\begin{array}{c}0.12^{* * *} \\
(0.03)\end{array}$ & $\begin{array}{c}0.10^{* * *} \\
(0.04)\end{array}$ \\
\hline \multicolumn{8}{|l|}{ Socio-Demographics: } \\
\hline Black & & $\begin{array}{l}-0.04 \\
(0.04)\end{array}$ & & & & & $\begin{array}{l}-0.02 \\
(0.04)\end{array}$ \\
\hline Other & & $\begin{array}{l}-0.04 \\
(0.05)\end{array}$ & & & & & $\begin{array}{l}-0.05 \\
(0.05)\end{array}$ \\
\hline Male & & $\begin{array}{c}-0.06^{* *} \\
(0.02)\end{array}$ & & & & & $\begin{array}{c}-0.03 \\
(0.02)\end{array}$ \\
\hline Florida & & $\begin{array}{c}0.01 \\
(0.03)\end{array}$ & & & & & $\begin{array}{l}-0.00 \\
(0.03)\end{array}$ \\
\hline New York & & $\begin{array}{l}-0.03 \\
(0.03)\end{array}$ & & & & & $\begin{array}{c}-0.04 \\
(0.03)\end{array}$ \\
\hline Texas & & $\begin{array}{l}-0.05 \\
(0.03)\end{array}$ & & & & & $\begin{array}{l}-0.04 \\
(0.03)\end{array}$ \\
\hline 56 or Older & & $\begin{array}{c}-0.05^{* *} \\
(0.02)\end{array}$ & & & & & $\begin{array}{c}-0.02 \\
(0.03)\end{array}$ \\
\hline \multicolumn{8}{|l|}{ Health: } \\
\hline Diabetes & & & $\begin{array}{l}-0.05 \\
(0.03)\end{array}$ & & & & $\begin{array}{c}-0.05^{*} \\
(0.03)\end{array}$ \\
\hline High Blood Pressure & & & $\begin{array}{l}-0.03 \\
(0.03)\end{array}$ & & & & $\begin{array}{c}-0.01 \\
(0.03)\end{array}$ \\
\hline Heart Disease & & & $\begin{array}{c}0.03 \\
(0.05)\end{array}$ & & & & $\begin{array}{c}0.02 \\
(0.05)\end{array}$ \\
\hline Asthma & & & $\begin{array}{c}0.04 \\
(0.03)\end{array}$ & & & & $\begin{array}{c}0.04 \\
(0.03)\end{array}$ \\
\hline Allergies & & & $\begin{array}{c}0.04 \\
(0.02)\end{array}$ & & & & $\begin{array}{c}0.02 \\
(0.02)\end{array}$ \\
\hline Other Condition & & & $\begin{array}{l}0.06^{* *} \\
(0.03)\end{array}$ & & & & $\begin{array}{l}0.06^{* *} \\
(0.03)\end{array}$ \\
\hline Housing: & & & & & & & \\
\hline Semi-urban / residential & & & & $\begin{array}{l}-0.03 \\
(0.02)\end{array}$ & & & $\begin{array}{l}-0.03 \\
(0.02)\end{array}$ \\
\hline
\end{tabular}




\begin{tabular}{|c|c|c|c|}
\hline Countryside & $\begin{array}{c}-0.08^{* *} \\
(0.04)\end{array}$ & & $\begin{array}{l}-0.05 \\
(0.04)\end{array}$ \\
\hline No Access to Open Air & $\begin{array}{l}-0.04 \\
(0.03)\end{array}$ & & $\begin{array}{c}0.00 \\
(0.03)\end{array}$ \\
\hline \multicolumn{4}{|c|}{ Work Arrangements-Losses: } \\
\hline Stopped Working & $\begin{array}{c}0.10^{* *} \\
(0.04)\end{array}$ & & $\begin{array}{c}0.07 \\
(0.04)\end{array}$ \\
\hline Began Tele-Working & $\begin{array}{c}0.12^{* * *} \\
(0.04)\end{array}$ & & $\begin{array}{c}0.09^{* *} \\
(0.04)\end{array}$ \\
\hline Not Observed Working & $\begin{array}{l}0.07^{*} \\
(0.04)\end{array}$ & & $\begin{array}{c}0.04 \\
(0.04)\end{array}$ \\
\hline Other & $\begin{array}{c}0.18^{* * *} \\
(0.04)\end{array}$ & & $\begin{array}{c}0.13^{* * *} \\
(0.04)\end{array}$ \\
\hline Flag extreme lost income & $\begin{array}{c}-0.05^{* *} \\
(0.03)\end{array}$ & & $\begin{array}{c}-0.03 \\
(0.03)\end{array}$ \\
\hline Lost HH Inc./\$1,000 Orig & $\begin{array}{l}-0.00 \\
(0.00)\end{array}$ & & $\begin{array}{c}0.00 \\
(0.00)\end{array}$ \\
\hline Lost HH Inc. $/ \$ 1,000 \mathrm{Adj}$. & $\begin{array}{c}0.02^{* * *} \\
(0.01)\end{array}$ & & $\begin{array}{c}0.01^{* *} \\
(0.01)\end{array}$ \\
\hline \multicolumn{4}{|l|}{ Beliefs-Perceptions: } \\
\hline Slightly effective & & $\begin{array}{l}0.24^{* *} \\
(0.10)\end{array}$ & $\begin{array}{l}0.23^{* *} \\
(0.10)\end{array}$ \\
\hline Moderately effective & & $\begin{array}{c}0.25^{* * *} \\
(0.10)\end{array}$ & $\begin{array}{c}0.24^{* *} \\
(0.10)\end{array}$ \\
\hline Very effective & & $\begin{array}{c}0.33^{* * *} \\
(0.09)\end{array}$ & $\begin{array}{c}0.32^{* * *} \\
(0.09)\end{array}$ \\
\hline Extremely effective & & $\begin{array}{c}0.37^{* * *} \\
(0.09)\end{array}$ & $\begin{array}{c}0.34^{\text {*** }} \\
(0.09)\end{array}$ \\
\hline Infected in Area & & $\begin{array}{c}0.04 \\
(0.04)\end{array}$ & $\begin{array}{c}0.01 \\
(0.04)\end{array}$ \\
\hline More Free Time & & $\begin{array}{c}0.02 \\
(0.02)\end{array}$ & $\begin{array}{c}0.01 \\
(0.02)\end{array}$ \\
\hline More Family Time & & $\begin{array}{l}0.05^{* *} \\
(0.02)\end{array}$ & $\begin{array}{l}0.04^{*} \\
(0.02)\end{array}$ \\
\hline Less Pollution & & $0.06^{* * *}$ & $0.06^{* *}$ \\
\hline
\end{tabular}




\begin{tabular}{|c|c|c|c|c|c|c|c|}
\hline & & & & & & $(0.02)$ & $(0.02)$ \\
\hline \multirow[t]{2}{*}{ Less Noise } & & & & & & -0.03 & -0.03 \\
\hline & & & & & & $(0.02)$ & $(0.02)$ \\
\hline \multirow[t]{2}{*}{ Other } & & & & & & 0.02 & 0.00 \\
\hline & & & & & & $(0.05)$ & $(0.05)$ \\
\hline Observations & 955 & 955 & 955 & 955 & 955 & 955 & 955 \\
\hline$R^{2}$ & 0.033 & 0.049 & 0.046 & 0.040 & 0.064 & 0.099 & 0.138 \\
\hline
\end{tabular}

Standard errors in parentheses

Linear probability models estimates for association between socidemographic characteristics and behavior change.

${ }^{*} p<0.1,{ }^{* *} p<0.05,{ }^{* * *} p<0.01$

Table A.6: Factors Associated with Social Distancing More-Previously Not

\begin{tabular}{|c|c|c|c|c|c|c|c|}
\hline & (1) & (2) & (3) & (4) & (5) & (6) & (7) \\
\hline \multicolumn{8}{|l|}{ Income: } \\
\hline \multirow[t]{2}{*}{ Second quintile } & $0.10^{*}$ & $0.12^{* *}$ & $0.09^{*}$ & 0.06 & $0.10^{*}$ & 0.08 & 0.08 \\
\hline & $(0.05)$ & $(0.05)$ & $(0.05)$ & $(0.05)$ & $(0.05)$ & $(0.05)$ & $(0.05)$ \\
\hline \multirow[t]{2}{*}{ Third quintile } & $0.14^{* * *}$ & $0.16^{* * *}$ & $0.13^{* *}$ & 0.09 & $0.15^{* * *}$ & $0.10^{* *}$ & $0.09^{*}$ \\
\hline & $(0.05)$ & $(0.05)$ & $(0.05)$ & $(0.05)$ & $(0.05)$ & $(0.05)$ & $(0.05)$ \\
\hline \multirow[t]{2}{*}{ Fourth quintile } & $0.15^{* * *}$ & $0.18^{* * *}$ & $0.14^{* * *}$ & $0.10^{*}$ & $0.17^{* * *}$ & $0.13^{* * *}$ & $0.12^{* *}$ \\
\hline & $(0.05)$ & $(0.05)$ & $(0.05)$ & $(0.05)$ & $(0.05)$ & $(0.05)$ & $(0.05)$ \\
\hline \multirow[t]{2}{*}{ Fifth quintile } & $0.22^{* * *}$ & $0.30^{* * *}$ & $0.22^{* * *}$ & $0.18^{* * *}$ & $0.26^{* * *}$ & $0.20^{* * *}$ & $0.20^{* * *}$ \\
\hline & $(0.05)$ & $(0.06)$ & $(0.06)$ & $(0.06)$ & $(0.06)$ & $(0.05)$ & $(0.06)$ \\
\hline \multicolumn{8}{|c|}{ Socio-Demographics: } \\
\hline \multirow[t]{2}{*}{ Black } & & -0.05 & & & & & -0.01 \\
\hline & & $(0.05)$ & & & & & $(0.05)$ \\
\hline \multirow[t]{2}{*}{ Other } & & -0.08 & & & & & $-0.15^{* *}$ \\
\hline & & $(0.08)$ & & & & & $(0.07)$ \\
\hline \multirow[t]{2}{*}{ Male } & & $-0.19^{* * *}$ & & & & & $-0.14^{* * *}$ \\
\hline & & $(0.03)$ & & & & & $(0.03)$ \\
\hline \multirow[t]{2}{*}{ Florida } & & $-0.13^{* * *}$ & & & & & $-0.15^{* * *}$ \\
\hline & & $(0.05)$ & & & & & $(0.04)$ \\
\hline \multirow[t]{2}{*}{ New York } & & -0.06 & & & & & -0.04 \\
\hline & & $(0.04)$ & & & & & $(0.04)$ \\
\hline \multirow[t]{2}{*}{ Texas } & & $-0.12^{* *}$ & & & & & $-0.11^{* *}$ \\
\hline & & $(0.05)$ & & & & & $(0.05)$ \\
\hline
\end{tabular}




\begin{tabular}{|c|c|c|c|}
\hline 56 or Older & $\begin{array}{c}0.05 \\
(0.03)\end{array}$ & & $\begin{array}{c}0.04 \\
(0.04)\end{array}$ \\
\hline \multicolumn{4}{|l|}{ Health: } \\
\hline Diabetes & $\begin{array}{l}-0.01 \\
(0.05)\end{array}$ & & $\begin{array}{c}0.02 \\
(0.04)\end{array}$ \\
\hline High Blood Pressure & $\begin{array}{c}0.01 \\
(0.04)\end{array}$ & & $\begin{array}{l}-0.01 \\
(0.04)\end{array}$ \\
\hline Heart Disease & $\begin{array}{c}-0.24^{* * *} \\
(0.07)\end{array}$ & & $\begin{array}{c}-0.21^{* * *} \\
(0.07)\end{array}$ \\
\hline Asthma & $\begin{array}{c}0.02 \\
(0.05)\end{array}$ & & $\begin{array}{c}0.01 \\
(0.05)\end{array}$ \\
\hline Allergies & $\begin{array}{c}0.03 \\
(0.04)\end{array}$ & & $\begin{array}{l}-0.01 \\
(0.04)\end{array}$ \\
\hline Other Condition & $\begin{array}{c}0.05 \\
(0.05)\end{array}$ & & $\begin{array}{c}0.01 \\
(0.05)\end{array}$ \\
\hline \multicolumn{4}{|l|}{ Housing: } \\
\hline Semi-urban / residential & & $\begin{array}{c}0.06 \\
(0.04)\end{array}$ & $\begin{array}{c}0.04 \\
(0.04)\end{array}$ \\
\hline Countryside & & $\begin{array}{c}0.02 \\
(0.06)\end{array}$ & $\begin{array}{l}-0.01 \\
(0.05)\end{array}$ \\
\hline No Access to Open Air & & $\begin{array}{c}-0.19^{* * *} \\
(0.05)\end{array}$ & $\begin{array}{c}-0.11^{* *} \\
(0.05)\end{array}$ \\
\hline \multicolumn{4}{|c|}{ Work Arrangements-Losses: } \\
\hline Stopped Working & & $\begin{array}{c}0.14^{* * *} \\
(0.05)\end{array}$ & $\begin{array}{c}0.08 \\
(0.05)\end{array}$ \\
\hline Began Tele-Working & & $\begin{array}{c}0.14^{* *} \\
(0.06)\end{array}$ & $\begin{array}{l}0.12^{* *} \\
(0.05)\end{array}$ \\
\hline Not Observed Working & & $\begin{array}{c}0.22^{* * *} \\
(0.05)\end{array}$ & $\begin{array}{l}0.12^{* *} \\
(0.05)\end{array}$ \\
\hline Other & & $\begin{array}{l}0.19^{* *} \\
(0.08)\end{array}$ & $\begin{array}{c}0.10 \\
(0.08)\end{array}$ \\
\hline Flag extreme lost income & & $\begin{array}{c}0.03 \\
(0.05)\end{array}$ & $\begin{array}{c}0.08 \\
(0.05)\end{array}$ \\
\hline Lost HH Inc. $/ \$ 1,000$ Orig & & $\begin{array}{l}-0.00 \\
(0.00)\end{array}$ & $\begin{array}{c}0.00 \\
(0.00)\end{array}$ \\
\hline
\end{tabular}


Lost HH Inc. $\$$ 1,000 Adj.

$0.04^{* * *}$

(0.01)

\section{Beliefs-Perceptions:}

Slightly effective

$0.16^{*}$

Moderately effective

Very effective

Extremely effective

Infected in Area

$-0.28^{* * *}$

More Free Time

More Family Time

Less Pollution

Less Noise

Other
0.11

$0.15^{*}$

$0.33^{* * *}$

(0.08)

$0.39^{* * *}$

0.01

$0.08^{* *}$

$0.17^{* * *}$

0.03

(0.04)

$0.03^{* * *}$

0.09 $0.27^{* * *}$

$0.30^{* * *}$

$-0.24^{* * *}$

0.01

$0.10^{* * *}$

$0.15^{* * *}$

0.02

$0.18^{* *}$

$0.15^{*}$

$(0.09)$

\begin{tabular}{lccccccc}
\hline Observations & 918 & 918 & 918 & 918 & 918 & 918 & 918 \\
$R^{2}$ & 0.019 & 0.071 & 0.030 & 0.038 & 0.057 & 0.135 & 0.206 \\
\hline \hline
\end{tabular}

Standard errors in parentheses

Linear probability models estimates for association between socidemographic characteristics and behavior change.

${ }^{*} p<0.1,{ }^{* *} p<0.05,{ }^{* * *} p<0.01$

Table A.7: Factors Associated with Increased Washing Hands-Wearing Mask

\begin{tabular}{lccccccc}
\hline \hline & $(1)$ & $(2)$ & $(3)$ & $(4)$ & $(5)$ & $(6)$ & $(7)$ \\
\hline Income: & & & & & & & \\
Second quintile & 0.07 & 0.07 & 0.06 & 0.05 & 0.07 & 0.06 & 0.05 \\
& $(0.05)$ & $(0.05)$ & $(0.05)$ & $(0.05)$ & $(0.05)$ & $(0.05)$ & $(0.05)$ \\
Third quintile & $0.19^{* * *}$ & $0.21^{* * *}$ & $0.19^{* * *}$ & $0.17^{* * *}$ & $0.20^{* * *}$ & $0.17^{* * *}$ & $0.17^{* * *}$ \\
\hline
\end{tabular}




\begin{tabular}{|c|c|c|c|c|c|c|c|}
\hline & $(0.05)$ & $(0.05)$ & $(0.05)$ & $(0.05)$ & $(0.05)$ & $(0.05)$ & $(0.05)$ \\
\hline \multirow[t]{2}{*}{ Fourth quintile } & $0.13^{* * *}$ & $0.15^{* * *}$ & $0.13^{* *}$ & $0.10^{*}$ & $0.15^{* * *}$ & $0.13^{* * *}$ & $0.11^{* *}$ \\
\hline & $(0.05)$ & $(0.05)$ & $(0.05)$ & $(0.05)$ & $(0.05)$ & $(0.05)$ & $(0.05)$ \\
\hline \multirow[t]{2}{*}{ Fifth quintile } & $0.20^{* * *}$ & $0.25^{* * *}$ & $0.22^{* * *}$ & $0.17^{* * *}$ & $0.24^{* * *}$ & $0.20^{* * *}$ & $0.19^{* * *}$ \\
\hline & $(0.05)$ & $(0.05)$ & $(0.05)$ & $(0.05)$ & $(0.05)$ & $(0.05)$ & $(0.06)$ \\
\hline \multicolumn{8}{|l|}{ Socio-Demographics: } \\
\hline \multirow[t]{2}{*}{ Black } & & $0.09^{*}$ & & & & & $0.13^{* * *}$ \\
\hline & & $(0.05)$ & & & & & $(0.05)$ \\
\hline \multirow[t]{2}{*}{ Other } & & 0.08 & & & & & 0.06 \\
\hline & & $(0.07)$ & & & & & $(0.07)$ \\
\hline \multirow[t]{2}{*}{ Male } & & $-0.06^{*}$ & & & & & -0.01 \\
\hline & & $(0.03)$ & & & & & $(0.03)$ \\
\hline \multirow[t]{2}{*}{ Florida } & & 0.02 & & & & & -0.00 \\
\hline & & $(0.04)$ & & & & & $(0.04)$ \\
\hline \multirow[t]{2}{*}{ New York } & & 0.04 & & & & & 0.05 \\
\hline & & $(0.04)$ & & & & & $(0.04)$ \\
\hline \multirow[t]{2}{*}{ Texas } & & -0.03 & & & & & -0.03 \\
\hline & & $(0.04)$ & & & & & $(0.04)$ \\
\hline \multirow[t]{2}{*}{56 or Older } & & $0.14^{* * *}$ & & & & & $0.13^{* * *}$ \\
\hline & & $(0.03)$ & & & & & $(0.04)$ \\
\hline \multicolumn{8}{|l|}{ Health: } \\
\hline \multirow[t]{2}{*}{ Diabetes } & & & $-0.07^{*}$ & & & & -0.06 \\
\hline & & & $(0.04)$ & & & & $(0.04)$ \\
\hline \multirow[t]{2}{*}{ High Blood Pressure } & & & $0.09^{* * *}$ & & & & 0.04 \\
\hline & & & $(0.03)$ & & & & $(0.03)$ \\
\hline \multirow[t]{2}{*}{ Heart Disease } & & & -0.05 & & & & -0.05 \\
\hline & & & $(0.08)$ & & & & $(0.07)$ \\
\hline \multirow[t]{2}{*}{ Asthma } & & & 0.05 & & & & 0.03 \\
\hline & & & $(0.04)$ & & & & $(0.04)$ \\
\hline \multirow[t]{2}{*}{ Allergies } & & & $0.08^{* *}$ & & & & $0.08^{* *}$ \\
\hline & & & $(0.03)$ & & & & $(0.03)$ \\
\hline \multirow[t]{2}{*}{ Other Condition } & & & $0.08^{*}$ & & & & 0.05 \\
\hline & & & $(0.05)$ & & & & $(0.04)$ \\
\hline \multicolumn{8}{|l|}{ Housing: } \\
\hline Semi-urban / residential & & & & -0.02 & & & $-0.06^{*}$ \\
\hline
\end{tabular}




\begin{tabular}{|c|c|c|c|}
\hline & $(0.03)$ & & $(0.03)$ \\
\hline \multirow[t]{2}{*}{ Countryside } & -0.04 & & -0.07 \\
\hline & $(0.05)$ & & $(0.05)$ \\
\hline \multirow[t]{2}{*}{ No Access to Open Air } & $-0.12^{* *}$ & & -0.07 \\
\hline & $(0.05)$ & & $(0.05)$ \\
\hline \multicolumn{4}{|c|}{ Work Arrangements-Losses: } \\
\hline \multirow[t]{2}{*}{ Stopped Working } & $0.19^{* * *}$ & & $0.13^{* *}$ \\
\hline & $(0.05)$ & & $(0.05)$ \\
\hline \multirow[t]{2}{*}{ Began Tele-Working } & $0.13^{* *}$ & & $0.13^{* *}$ \\
\hline & $(0.06)$ & & $(0.05)$ \\
\hline \multirow[t]{2}{*}{ Not Observed Working } & $0.19^{* * *}$ & & 0.08 \\
\hline & $(0.05)$ & & $(0.05)$ \\
\hline \multirow[t]{2}{*}{ Other } & $0.24^{* * *}$ & & $0.20^{* * *}$ \\
\hline & $(0.07)$ & & $(0.06)$ \\
\hline \multirow[t]{2}{*}{ Flag extreme lost income } & -0.02 & & -0.03 \\
\hline & $(0.05)$ & & $(0.05)$ \\
\hline \multirow[t]{2}{*}{ Lost HH Inc. $/ \$ 1,000$ Orig } & $-0.00^{* *}$ & & -0.00 \\
\hline & $(0.00)$ & & $(0.00)$ \\
\hline \multirow[t]{2}{*}{ Lost HH Inc. $/ \$ 1,000 \mathrm{Adj}$. } & $0.02^{* *}$ & & $0.02^{* *}$ \\
\hline & $(0.01)$ & & $(0.01)$ \\
\hline \multicolumn{4}{|l|}{ Beliefs-Perceptions: } \\
\hline \multirow[t]{2}{*}{ Slightly effective } & & -0.03 & -0.04 \\
\hline & & $(0.13)$ & $(0.13)$ \\
\hline \multirow[t]{2}{*}{ Moderately effective } & & 0.10 & 0.08 \\
\hline & & $(0.12)$ & $(0.12)$ \\
\hline \multirow[t]{2}{*}{ Very effective } & & $0.22^{*}$ & 0.19 \\
\hline & & $(0.11)$ & $(0.12)$ \\
\hline \multirow[t]{2}{*}{ Extremely effective } & & $0.30^{* * *}$ & $0.24^{* *}$ \\
\hline & & $(0.11)$ & $(0.12)$ \\
\hline \multirow[t]{2}{*}{ Infected in Area } & & $-0.20^{* * *}$ & $-0.20^{* * *}$ \\
\hline & & $(0.07)$ & $(0.07)$ \\
\hline \multirow[t]{2}{*}{ More Free Time } & & -0.04 & -0.04 \\
\hline & & $(0.03)$ & $(0.03)$ \\
\hline \multirow[t]{2}{*}{ More Family Time } & & -0.02 & 0.00 \\
\hline & & $(0.03)$ & $(0.03)$ \\
\hline
\end{tabular}




\begin{tabular}{|c|c|c|c|c|c|c|c|}
\hline Less Pollution & & & & & & $\begin{array}{c}0.09^{* * *} \\
(0.03)\end{array}$ & $\begin{array}{c}0.09^{* * *} \\
(0.03)\end{array}$ \\
\hline \multirow[t]{2}{*}{ Less Noise } & & & & & & 0.05 & 0.04 \\
\hline & & & & & & $(0.03)$ & $(0.03)$ \\
\hline \multirow[t]{2}{*}{ Other } & & & & & & 0.09 & 0.05 \\
\hline & & & & & & $(0.07)$ & $(0.07)$ \\
\hline Observations & 891 & 891 & 891 & 891 & 891 & 891 & 891 \\
\hline$R^{2}$ & 0.026 & 0.058 & 0.046 & 0.034 & 0.059 & 0.120 & 0.175 \\
\hline
\end{tabular}

Standard errors in parentheses

Linear probability models estimates for association between socidemographic characteristics and behavior change.

${ }^{*} p<0.1,{ }^{* *} p<0.05,{ }^{* * *} p<0.01$ 